NBER WORKING PAPER SERIES

HOW EFFICIENT IS DYNAMIC COMPETITION? THE CASE OF PRICE AS INVESTMENT

\author{
David Besanko \\ Ulrich Doraszelski \\ Yaroslav Kryukov \\ Working Paper 23829 \\ http://www.nber.org/papers/w23829 \\ NATIONAL BUREAU OF ECONOMIC RESEARCH \\ 1050 Massachusetts Avenue \\ Cambridge, MA 02138 \\ September 2017
}

We thank Guy Arie, Joe Harrington, Bruno Jullien, Ariel Pakes, Robert Porter, Michael Raith, Mike Riordan, Juuso Valimaki, and Mike Whinston for helpful discussions and suggestions. We also thank participants at seminars at Carnegie Mellon University, DG Comp at the European Commission, Helsinki Center for Economic Research, Johns Hopkins University, Toulouse School of Economics, Tulane University, and University of Rochester for their useful questions and comments. The views expressed herein are those of the authors and do not necessarily reflect the views of the National Bureau of Economic Research.

At least one co-author has disclosed a financial relationship of potential relevance for this research. Further information is available online at http://www.nber.org/papers/w23829.ack

NBER working papers are circulated for discussion and comment purposes. They have not been peer-reviewed or been subject to the review by the NBER Board of Directors that accompanies official NBER publications.

(C) 2017 by David Besanko, Ulrich Doraszelski, and Yaroslav Kryukov. All rights reserved. Short sections of text, not to exceed two paragraphs, may be quoted without explicit permission provided that full credit, including $\odot$ notice, is given to the source. 
How Efficient is Dynamic Competition? The Case of Price as Investment

David Besanko, Ulrich Doraszelski, and Yaroslav Kryukov

NBER Working Paper No. 23829

September 2017

JEL No. D21,D43,L13,L41

\section{ABSTRACT}

We study industries where the price that a firm sets serves as an investment into lower cost or higher demand. We assess the welfare implications of the ensuing competition for the market using analytical and numerical approaches to compare the equilibria of a learning-by-doing model to the first-best planner solution. We show that dynamic competition leads to low deadweight loss. This cannot be attributed to similarity between the equilibria and the planner

solution. Instead, we show how learning-by-doing causes the various contributions to deadweight loss to either be small or partly offset each other.

David Besanko

Department of Strategy

Kellogg School of Management

Northwestern University

2211 Campus Drive

Evanston, IL 60208

d-besanko@kellogg.northwestern.edu

Ulrich Doraszelski

The Wharton School

University of Pennsylvania

3620 Locust Walk

Philadelphia, PA 19104

and NBER

doraszelski@wharton.upenn.edu
Yaroslav Kryukov

University of Pittsburgh Medical Center

Pittsburgh, PA 15219

yaro.kryukov@gmail.com 


\title{
How Efficient is Dynamic Competition? The Case of Price as Investment*
}

\author{
David Besanko $^{\dagger} \quad$ Ulrich Doraszelski $^{\ddagger} \quad$ Yaroslav Kryukov $^{\S}$
}

September 4, 2017

\begin{abstract}
We study industries where the price that a firm sets serves as an investment into lower cost or higher demand. We assess the welfare implications of the ensuing competition for the market using analytical and numerical approaches to compare the equilibria of a learning-by-doing model to the first-best planner solution. We show that dynamic competition leads to low deadweight loss. This cannot be attributed to similarity between the equilibria and the planner solution. Instead, we show how learning-by-doing causes the various contributions to deadweight loss to either be small or partly offset each other.
\end{abstract}

\section{Introduction}

In many important industrial settings, the price that a firm sets plays the role of an investment. The investment role arises when the firm's price affects not only its current profit but also its future competitive position vis-à-vis its rivals. Examples include competition to accumulate production experience on a learning curve or to acquire a customer base in markets with network effects or switching costs. In these settings, a firm's current sales translate into lower cost or higher demand in the future, and the firm is thus able to shape the evolution of the industry by pricing aggressively. The emergence of "big data" and the increased recognition of the importance of customer data obtained over time as a byproduct of sales - summarized by the popular catch phrase "data is the new oil of the digital economy" - may make the investment role of price even more pervasive.

\footnotetext{
${ }^{*}$ We thank Guy Arie, Joe Harrington, Bruno Jullien, Ariel Pakes, Robert Porter, Michael Raith, Mike Riordan, Juuso Välimäki, and Mike Whinston for helpful discussions and suggestions. We also thank participants at seminars at Carnegie Mellon University, DG Comp at the European Commission, Helsinki Center for Economic Research, Johns Hopkins University, Toulouse School of Economics, Tulane University, and University of Rochester for their useful questions and comments.

${ }^{\dagger}$ Kellogg School of Management, Northwestern University, Evanston, IL 60208, dbesanko@kellogg.northwestern.edu.

${ }^{\ddagger}$ Wharton School, University of Pennsylvania, Philadelphia, PA 19104, doraszelski@wharton.upenn.edu.

${ }^{\S}$ University of Pittsburgh Medical Center, Pittsburgh, PA 15219, yaro.kryukov@gmail.com.
} 
It is well understood that the investment role of price opens up a second dimension of competition between firms, namely competition for the market. Competition is dynamic as firms jostle for competitive advantage through the prices they set. For example, in their review of the literature on network effects and switching costs, Farrell \& Klemperer (2007) point out that

[f]or a firm, it [the presence of switching costs and proprietary network effects] makes market share a valuable asset, and encourages a competitive focus on affecting expectations and on signing up pivotal (notably early) customers, which is reflected in strategies such as penetration pricing; competition is shifted from textbook competition in the market to a form of Schumpeterian competition for the market in which firms struggle for dominance. (p. 1976)

This jostle for competitive advantage is a feature of both "new economy" industries (e.g., Amazon versus Barnes \& Noble in e-book readers or Microsoft versus Sony in video game consoles) and "old economy" industries (e.g., Boeing versus Airbus in aircraft and Intel versus $\mathrm{AMD}$ in microprocessors).

At the same time, several high-profile antitrust cases, such as United States v. Microsoft in the late 1990s and European Union v. Google initiated in 2015 have taken aim at the market leaders in industries where the investment role of price is presumably important. This raises a question that is less well understood: does unfettered competition for the market when price serves as an investment warrant regulatory scrutiny? The answer depends on how efficient dynamic competition is. If it is not very efficient and leads to high deadweight loss, then there potentially are gains to be had from intervening in the industry. However, if dynamic competition is very efficient, then the upside from regulatory scrutiny is limited, barring explicitly anti-competitive behavior. The goal of this paper is hence to take a step toward assessing the efficiency of dynamic competition when price serves as an investment.

It may seem intuitive that dynamic competition when price serves as an investment is fairly efficient. This intuition becomes apparent by drawing a contrast with the rent-seeking literature (Posner 1975). In rent-seeking models, firms compete for market dominance by engaging in socially wasteful activities (e.g., lobbying). When price serves as an investment, firms also compete for market dominance, though not through socially wasteful activities but instead through low prices that transfer surplus to consumers. As a by-product of these low prices, firms generate socially valuable learning economies in production or demand-side economies of scale.

However, this intuition is incomplete. First, prices that are too low relative to marginal cost can cause deadweight loss from over-production, just as prices that are too high can cause deadweight loss from under-production. Second, dynamic competition may give rise to 
equilibria that entail predation-like behavior and monopolization of the industry in the long run (Dasgupta \& Stiglitz 1988, Cabral \& Riordan 1994, Athey \& Schmutzler 2001, Besanko, Doraszelski, Kryukov \& Satterthwaite 2010, Besanko, Doraszelski \& Kryukov 2014). This can cause welfare losses from monopoly pricing and suboptimal product variety. Third, as firms attempt to balance the gains from possibly monopolizing their industry against the losses from pricing aggressively as they jostle for competitive advantage, dynamic competition can distort entry behavior and result in coordination failures similar to the ones in natural monopoly markets highlighted by Bolton \& Farrell (1990). Finally, dynamic competition can also distort exit behavior if firms are reluctant to exit an industry destined to be monopolized and become caught up in wars of attrition (Maynard Smith 1974, Tirole 1988, Bulow \& Klemperer 1999).

In sum, dynamic competition when price serves as an investment may cause deadweight losses through a number of distinct channels, and it is not a priori obvious what the magnitude of these deadweight losses may be. In this paper, we make a first attempt to assess how efficient dynamic competition is. We do so in a model of learning-by-doing along the lines of Cabral \& Riordan (1994), Besanko et al. (2010), and Besanko et al. (2014) that involves price competition in a differentiated products market with entry and exit. Learning-by-doing is not only an important setting in its own right 1 but also shares key features with other settings such as network effects and switching costs (Besanko et al. 2014).

We use a combination of analytical and numerical approaches to compare the Markov perfect equilibria of our learning-by-doing model to the solution of a first-best problem that has a social planner controlling pricing, entry, and exit decisions. Deadweight loss is the difference in the expected net present value of total surplus. We carefully explore the parameter space and multiple equilibria using the homotopy or path-following method in Besanko et al. (2010). We show that dynamic competition does indeed tend to lead to low deadweight loss. Deadweight loss is less than $10 \%$ of the maximum value added by the industry in more than $65 \%$ of parameterizations and less than $20 \%$ of value added in more than $90 \%$ of parameterizations 2 Moreover, the investment role of price tends to be socially beneficial; if we shut it down, then deadweight loss increases - often substantially - in more than $80 \%$ of parameterizations.

We then point out that low deadweight loss does not arise because equilibrium behavior

\footnotetext{
${ }^{1}$ For empirical studies of learning-by-doing in a broad set of industries, see Wright (1936), Hirsch (1952), DeJong (1957), Alchian (1963), Levy (1965), Kilbridge (1962), Hirschmann (1964), Preston \& Keachie (1964), Baloff (1971), Dudley (1972), Zimmerman (1982), Lieberman (1984), Gruber (1992), Irwin \& Klenow (1994), Jarmin (1994), Pisano (1994), Bohn (1995), Hatch \& Mowery (1998), Benkard (2000), Shafer, Nembhard \& Uzumeri (2001), Thompson (2001), and Thornton \& Thompson (2001).

${ }^{2}$ The maximum value added by the industry is the difference in the expected net present value of total surplus of the first-best planner solution and an industry that remains empty forever. We explain the rationale for this normalization in Section 3.2 .
} 
and the industry dynamics that it implies are similar to the first-best planner solution. On the contrary, especially the "best" equilibria that entail the lowest deadweight loss are remarkably different from the first-best planner solution. We further show in an analytically tractable special case of our learning-by-doing model that there is nothing about dynamic competition when price serves as an investment that precludes potentially costly distortions in equilibrium entry and exit behavior. Too much or early entry, respectively, too little or late entry lead to wasteful duplication and delay (Bolton \& Farrell 1990), and too much or early exit, respectively, too little or late exit similarly lead to welfare losses. In addition, what we call cost-inefficient exit leads to welfare losses if a lower-cost firm exits the industry while a higher-cost firm does not.

We next seek to identify the mechanisms through which dynamic competition leads to low deadweight loss. We decompose deadweight loss into a pricing distortion that captures differences in equilibrium pricing behavior from the first-best planner solution and a remaining non-pricing distortion that subsumes a suboptimal number of firms and products being offered by these firms, a suboptimal exploitation of learning economies, and cost-inefficient exit. The low deadweight loss boils down to three regularities in these components.

First, while the pricing distortion tends to be the largest contributor to deadweight loss, in the best equilibria it is quite low and it is "not so bad" in the "worst" equilibria that entail the highest deadweight loss. We provide analytical bounds on the pricing distortion. The bounds make plain that this regularity is rooted in learning-by-doing itself. In particular, the bounds tighten as firms move down their learning curves and improve their cost positions. Second, the non-pricing distortion in the worst equilibria tends to be low because competition for the market resolves itself quickly and winnows out firms in a fairly efficient way. Third, in the best equilibria the non-pricing distortion tends to be higher. Dynamic competition tends to lead to over-entry and under-exit 3 Too many firms have social costs in terms of incurred setup costs and forgone scrap values but also offsetting social benefits in terms of additional product variety. Learning-by-doing again accentuates these benefits by making the additional product variety less costly to procure.

All in all, we show that dynamic competition when price serves as an investment works remarkably well, not because competition for the market is a "magic bullet" that achieves full efficiency, but because the various contributions to deadweight loss either are small or partly offset each other. And this, in turn, happens because of learning-by-doing itself.

Related literature. Our paper is related to a large literature on dynamic competition in settings where price plays an investment role. Besides the aforementioned models of learning-

\footnotetext{
${ }^{3}$ Interestingly, this contrasts with static models of imperfect competition with free entry (Dixit \& Stiglitz 1977, Koenker \& Perry 1981, Besanko, Perry \& Spady 1990, Anderson, de Palma \& Thisse 1992).
} 
by-doing, this includes the models of network effects in Mitchell \& Skrzypacz (2006), Chen, Doraszelski \& Harrington (2009), Dube, Hitsch \& Chintagunta (2010), and Cabral (2011); switching costs in Dube, Hitsch \& Rossi (2009) and Chen (2011); experience goods in Bergemann \& Välimäki (1996) and Ching (2010); and habit formation in Bergemann \& Välimäki (2006). As we show in Besanko et al. (2014), these models share key features with our leaning-by-doing model. In particular, a firm has two distinct motives for pricing aggressively, namely to acquire competitive advantage or overcome competitive disadvantage - the so-called advantage-building motive - and to prevent its rivals from acquiring competitive advantage - the advantage-denying motive 4

While the literature has generally focused on characterizing equilibrium behavior rather than anatomizing its implications for welfare, it has raised some red flags regarding the efficiency of dynamic competition. Bergemann \& Välimäki (1997) show that the equilibrium in their experience-goods model is inefficient because of an informational externality between firms (see also Rob (1991) and Bolton \& Harris (1999)). The literature on network effects shows that an inferior product can be adopted and persist as the standard either because consumers' expectations are misaligned or favor the inferior product (Biglaiser \& Cremer 2016, Halaburda, Jullien \& Yehezkel 2016). Nevertheless, none of these papers directly addresses the question whether the investment role of price is socially beneficial. Our learning-by-doing model also focuses more directly on entry and exit as generic elements of models of firm and industry dynamics (Jovanovic 1982, Hopenhayn 1992, Ericson \& Pakes 1995).

Competition for the market is often conceptualized through sequential winner-take-all $\mathrm{R} \& \mathrm{D}$ races to produce disruptive innovations. In these Schumpeterian models of creative destruction, an incumbent temporarily assumes a monopoly position only to be dislodged by an entrant who has successfully invested in a superior technology (Aghion \& Howitt 1992). Evans \& Schmalensee (2002) argue that an excessive focus on short-run market power in this setting can obscure just how vulnerable to disruptive innovations market leaders can be, a perspective that has influenced the direction of antitrust policy in the U.S. as it pertains to high-tech industries. Segal \& Whinston (2007) show that antitrust policies that protect entrants at the expense of incumbents can have the salutary effect of increasing the rate of innovation. Our paper complements this literature by investigating the welfare implications of competition for the market in a very different type of setting, namely one where price

\footnotetext{
${ }^{4}$ The advantage-denying motive also arises in price-setting models with costly quantity or capacity adjustment and, perhaps more surprisingly, quantity-setting models with costly price adjustments (menu costs). This is because in these latter models a firm's quantity has a direct effect on its rival's price in the current period and thus competitive position in the subsequent period (see Lapham \& Ware (1994) and Jun \& Vives (2004) and the references therein). Finally, the advantage-denying motive arises in some investment models, such as advertising models where goodwill accumulates according to a firm's "share of voice" or advertising is combative (see Jorgensen \& Zaccour (2004) and the references therein).
} 
takes on the role of the investment.

Finally, similar to our analysis, Pakes \& McGuire's (1994) find in a quality-ladder model that deadweight loss can be quite low even though equilibrium behavior and industry dynamics differ markedly from the first-best planner solution. Different from our analysis, however, this finding pertains to a single parameterization, so it is not clear to what extent it generalizes. In addition, in the quality-ladder model price does again not serve as an investment, meaning that the mechanisms through which dynamic competition leads to low deadweight loss are different.

Organization of paper. The remainder of this paper is organized as follows. Section 2 sets up our learning-by-doing model. Section 3 develops the first-best planner problem and the welfare metrics we use in the subsequent analysis. Section 4 provides an analytical characterization of equilibria and associated deadweight loss for a special case of our model. Sections 5 and 6 present our numerical analysis of equilibria and associated deadweight loss over a wide range of the parameter space and summarize the regularities that emerge. Section 7 introduces our decomposition of deadweight loss and provides analytical bounds on some of its components. Section 8 ties together the insights from the preceding sections and offers a summary explanation of why dynamic competition leads to low deadweight loss when price serves as an investment.

Throughout the paper we distinguish between propositions that are established through formal arguments and results. A result either establishes a possibility through a numerical example or summarizes a regularity through a systematic exploration of the parameter space. Unless indicated otherwise, proofs of propositions are in the Appendix. The Online Appendix contains additional results and technical details to support the analysis in the paper.

\section{Model}

We study a discrete-time, infinite-horizon dynamic stochastic game between two firms in an industry that is characterized by learning-by-doing. At any point in time, firm $n \in\{1,2\}$ is described by its state $e_{n} \in\{0,1, \ldots, M\}$. A firm can be either an incumbent firm that actively produces or a potential entrant. State $e_{n}=0$ indicates a potential entrant. States

$e_{n} \in\{1, \ldots, M\}$ indicate the cumulative experience or stock of know-how of an incumbent firm. By making a sale in the current period, an incumbent firm can add to its stock of knowhow and, through learning-by-doing, lower its production cost in the subsequent period. Competitive advantage and industry leadership are therefore determined endogenously in our model. The industry's state is the vector of firms' states $\mathbf{e}=\left(e_{1}, e_{2}\right)$. It completely describes the number of incumbent firms - and therefore the extent of product variety- 
along with their cost positions. If $e_{1}>e_{2}\left(e_{1}<e_{2}\right)$, then we refer to firm 1 as the leader (follower) and to firm 2 as the follower (leader).

In each period, firms first set prices and then decide on exit and entry. During the pricesetting phase, the state changes from $\mathbf{e}$ to $\mathbf{e}^{\prime}$ depending on the outcome of the pricing game between the incumbent firms. In particular, if firm 1 makes the sale and adds to its stock of know-how, the state changes to $\mathbf{e}^{\prime}=\mathbf{e}^{1+}=\left(\min \left\{e_{1}+1, M\right\}, e_{2}\right)$; if firm 2 makes the sale, the state changes to $\mathbf{e}^{\prime}=\mathbf{e}^{2+}=\left(e_{1}, \min \left\{e_{2}+1, M\right\}\right)$.

During the exit-entry phase, the state then changes from $\mathbf{e}^{\prime}$ to $\mathbf{e}^{\prime \prime}$ depending on the exit decisions of the incumbent firms and the entry decisions of the potential entrants. We model the entry of firm $n$ as a transition from state $e_{n}^{\prime}=0$ to state $e_{n}^{\prime \prime}=1$ and exit as a transition from state $e_{n}^{\prime} \geq 1$ to state $e_{n}^{\prime \prime}=0$. As the exit of an incumbent firm creates an opportunity for a potential entrant to enter the industry, re-entry is possible. The state at the end of the current period finally becomes the state at the beginning of the subsequent period.

Before analyzing firms' decisions and the equilibrium of our dynamic stochastic game, we describe the remaining primitives.

Learning-by-doing and production cost. Incumbent firm n's marginal cost of production $c\left(e_{n}\right)$ depends on its stock of know-how through a learning curve with a progress ratio $\rho \in[0,1]:$

$$
c\left(e_{n}\right)=\left\{\begin{array}{llc}
\kappa \rho^{\log _{2} e_{n}} & \text { if } & 1 \leq e_{n}<m, \\
\kappa \rho^{\log _{2} m} & \text { if } & m \leq e_{n} \leq M .
\end{array}\right.
$$

Because marginal cost decreases by $100(1-\rho) \%$ as the stock of know-how doubles, a lower progress ratio implies stronger learning economies.

The marginal cost for a firm without prior experience, $c(1)$, is $\kappa>0$. Once the firm reaches state $m$, the learning curve "bottoms out," and there are no further experiencebased cost reductions. We accordingly refer to an industry in state e as a mature duopoly if $\mathbf{e} \geq(m, m)$ and as a mature monopoly if either $e_{1} \geq m$ and $e_{2}=0$ or $e_{1}=0$ and $e_{2} \geq m$.

Demand. The industry draws customers from a large pool of potential buyers. One buyer enters the market each period and purchases one unit of either one of the "inside goods" that are offered by the incumbent firms at prices $\mathbf{p}=\left(p_{1}, p_{2}\right)$ or an "outside good" at an exogenously given price $p_{0}$. The probability that firm $n$ makes the sale is given by the logit specification

$$
D_{n}(\mathbf{p})=\frac{\exp \left(\frac{v-p_{n}}{\sigma}\right)}{\sum_{k=0}^{2} \exp \left(\frac{v-p_{k}}{\sigma}\right)}=\frac{\exp \left(\frac{-p_{n}}{\sigma}\right)}{\sum_{k=0}^{2} \exp \left(\frac{-p_{k}}{\sigma}\right)},
$$

where $v$ is gross utility and $\sigma>0$ is a scale parameter that governs the degree of product differentiation. As $\sigma \rightarrow 0$, goods become homogeneous and the firm that sets the lowest price 
makes the sale for sure 5 If firm $n$ is a potential entrant, then we set its price to infinity so that $D_{n}(\mathbf{p})=0$.

Throughout we assume that the outside good is supplied competitively and priced at its marginal cost of production $c_{0} \geq 0$. The price of the outside good $p_{0}=c_{0}$ determines the overall level of demand for the inside goods. As it decreases, the market becomes smaller, and ultimately the industry is no longer viable.

Scrap values and setup costs. To facilitate the subsequent computations, we "purify" mixed exit and entry strategies. If incumbent firm $n$ exits the industry, it receives a scrap value $X_{n}$ drawn from a symmetric triangular distribution $F_{X}(\cdot)$ with support $\left[\bar{X}-\Delta_{X}, \bar{X}+\right.$ $\left.\Delta_{X}\right]$, where $E_{X}\left(X_{n}\right)=\bar{X}$ and $\Delta_{X}>0$ is a scale parameter. If potential entrant $n$ enters the industry, it incurs a setup cost $S_{n}$ drawn from a symmetric triangular distribution $F_{S}(\cdot)$ with support $\left[\bar{S}-\Delta_{S}, \bar{S}+\Delta_{S}\right]$, where $E_{S}\left(S_{n}\right)=\bar{S}$ and $\Delta_{S}>0$ is a scale parameter. Scrap values and setup costs are independently and identically distributed across firms and periods, and their realization is observed by the firm but not its rival.

Although in our model a firm formally follows a pure strategy in making its exit or entry decision, the dependence of its decision on its randomly drawn, privately known scrap value, respectively, setup cost implies that its rival perceives the firm as if it was following a mixed strategy. As $\Delta_{X} \rightarrow 0$ and $\Delta_{S} \rightarrow 0$, the scrap value is fixed at $\bar{X}$ and the setup cost at $\bar{S}$ and we revert to mixed exit and entry strategies (Doraszelski \& Satterthwaite 2010, Doraszelski \& Escobar 2010).

\subsection{Firms' decisions}

To analyze the pricing and exit decisions of incumbent firms and the entry decisions of potential entrants, we work backwards from the exit-entry phase to the price-setting phase. Combining exit and entry decisions, we let $\phi_{n}\left(\mathbf{e}^{\prime}\right)$ denote the probability, as viewed from the perspective of its rival, that firm $n$ decides not to operate in state $\mathbf{e}^{\prime}$ : if $e_{n}>0$ so that firm $n$ is an incumbent, then $\phi_{n}\left(\mathbf{e}^{\prime}\right)$ is the probability of exiting; if $e_{n}^{\prime}=0$ so that firm $n$ is an entrant, then $\phi_{n}\left(\mathbf{e}^{\prime}\right)$ is the probability of not entering.

We use $V_{n}(\mathbf{e})$ to denote the expected net present value (NPV) of future cash flows to firm $n$ in state e at the beginning of the period and $U_{n}\left(\mathbf{e}^{\prime}\right)$ to denote the expected NPV of future cash flows to firm $n$ in state $\mathbf{e}^{\prime}$ after pricing decisions but before exit and entry decisions are made. The price-setting phase determines the value function $\mathbf{V}_{n}$ along with the policy function $\mathbf{p}_{n}$ with typical element $V_{n}(\mathbf{e})$, respectively, $p_{n}(\mathbf{e})$; the exit-entry phase determines the value function $\mathbf{U}_{n}$ along with the policy function $\phi_{n}$ with typical element $U_{n}\left(\mathbf{e}^{\prime}\right)$, respectively, $\phi_{n}\left(\mathbf{e}^{\prime}\right)$.

\footnotetext{
${ }^{5}$ If there is more than one such firm, each of them makes the sale with equal probability.
} 
Exit decision of incumbent firm. To simplify the exposition, we focus on firm 1; the derivations for firm 2 are analogous. If incumbent firm 1 exits the industry, it receives the scrap value $X_{1}$ in the current period and perishes. If it does not exit, its expected NPV is

$$
\widehat{X}_{1}\left(\mathbf{e}^{\prime}\right)=\beta\left[V_{1}\left(\mathbf{e}^{\prime}\right)\left(1-\phi_{2}\left(\mathbf{e}^{\prime}\right)\right)+V_{1}\left(e_{1}^{\prime}, 0\right) \phi_{2}\left(\mathbf{e}^{\prime}\right)\right],
$$

where $\beta \in[0,1)$ is the discount factor. The probability of incumbent firm 1 exiting the industry in state $\mathbf{e}^{\prime}$ is therefore $\phi_{1}\left(\mathbf{e}^{\prime}\right)=E_{X}\left[1\left[X_{1} \geq \widehat{X}_{1}\left(\mathbf{e}^{\prime}\right)\right]\right]=1-F_{X}\left(\widehat{X}_{1}\left(\mathbf{e}^{\prime}\right)\right)$, where $1[\cdot]$ is the indicator function and $\widehat{X}_{1}\left(\mathbf{e}^{\prime}\right)$ is the critical level of the scrap value above which exit occurs. Moreover, the expected NPV of incumbent firm 1 in the exit-entry phase is given by the Bellman equation

$$
\begin{gathered}
U_{1}\left(\mathbf{e}^{\prime}\right)=E_{X}\left[\max \left\{\widehat{X}_{1}\left(\mathbf{e}^{\prime}\right), X_{1}\right\}\right] \\
=\left(1-\phi_{1}\left(\mathbf{e}^{\prime}\right)\right) \beta\left[V_{1}\left(\mathbf{e}^{\prime}\right)\left(1-\phi_{2}\left(\mathbf{e}^{\prime}\right)\right)+V_{1}\left(e_{1}^{\prime}, 0\right) \phi_{2}\left(\mathbf{e}^{\prime}\right)\right]+\phi_{1}\left(\mathbf{e}^{\prime}\right) E_{X}\left[X_{1} \mid X_{1} \geq \widehat{X}_{1}\left(\mathbf{e}^{\prime}\right)\right],
\end{gathered}
$$

where $E_{X}\left[X_{1} \mid X_{1} \geq \widehat{X}_{1}\left(\mathbf{e}^{\prime}\right)\right]$ is the expectation of the scrap value conditional on exiting the industry.

Entry decision of potential entrant. There is a large queue of potential entrants. Depending on the number of incumbent firms, up to two potential entrants can enter the industry in each period. If a potential entrant does not enter, it perishes. If it enters, it becomes an incumbent firm without prior experience in the subsequent period. Hence, upon entry, the expected NPV of potential entrant 1 is

$$
\widehat{S}_{1}\left(\mathbf{e}^{\prime}\right)=\beta\left[V_{1}\left(1, e_{2}^{\prime}\right)\left(1-\phi_{2}\left(\mathbf{e}^{\prime}\right)\right)+V_{1}(1,0) \phi_{2}\left(\mathbf{e}^{\prime}\right)\right]
$$

In addition, potential entrant 1 incurs the setup cost $S_{1}$ in the current period. The probability of potential entrant 1 not entering the industry in state $\mathbf{e}^{\prime}$ is therefore $\phi_{1}\left(\mathbf{e}^{\prime}\right)=$ $E_{S}\left[1\left[S_{1} \geq \widehat{S}_{1}\left(\mathbf{e}^{\prime}\right)\right]\right]=1-F_{S}\left(\widehat{S}_{1}\left(\mathbf{e}^{\prime}\right)\right)$, where $\widehat{S}_{1}\left(\mathbf{e}^{\prime}\right)$ is the critical level of the setup cost below which entry occurs. Moreover, the expected NPV of potential entrant 1 in the exit-entry phase is given by the Bellman equation

$$
\begin{gathered}
U_{1}\left(\mathbf{e}^{\prime}\right)=E_{S}\left[\max \left\{\widehat{S}_{1}\left(\mathbf{e}^{\prime}\right)-S_{1}, 0\right\}\right] \\
=\left(1-\phi_{1}\left(\mathbf{e}^{\prime}\right)\right)\left\{\beta\left[V_{1}\left(1, e_{2}^{\prime}\right)\left(1-\phi_{2}\left(\mathbf{e}^{\prime}\right)\right)+V_{1}(1,0) \phi_{2}\left(\mathbf{e}^{\prime}\right)\right]-E_{S}\left[S_{1} \mid S_{1} \leq \widehat{S}_{1}\left(\mathbf{e}^{\prime}\right)\right]\right\},
\end{gathered}
$$


where $E_{S}\left[S_{1} \mid S_{1} \leq \widehat{S}_{1}\left(\mathbf{e}^{\prime}\right)\right]$ is the expectation of the setup cost conditional on entering the industry 6

Pricing decision of incumbent firm. In the price-setting phase, the expected NPV of incumbent firm 1 is

$$
\begin{gathered}
V_{1}(\mathbf{e})=\max _{p_{1}} D_{1}\left(p_{1}, p_{2}(\mathbf{e})\right)\left(p_{1}-c\left(e_{1}\right)\right)+\sum_{n=0}^{2} D_{n}\left(p_{1}, p_{2}(\mathbf{e})\right) U_{1}\left(\mathbf{e}^{n+}\right) \\
=\max _{p_{1}} D_{1}\left(p_{1}, p_{2}(\mathbf{e})\right)\left(p_{1}-c\left(e_{1}\right)\right)+U_{1}(\mathbf{e})+\sum_{n=1}^{2} D_{n}\left(p_{1}, p_{2}(\mathbf{e})\right)\left[U_{1}\left(\mathbf{e}^{n+}\right)-U_{1}(\mathbf{e})\right],
\end{gathered}
$$

where we let $\mathbf{e}^{0+}=\mathbf{e}$ and use the fact that $\sum_{n=0}^{2} D_{n}(\mathbf{p})=1$. Because the maximand on the right-hand side of Bellman equation (4) is strictly quasiconcave in $p_{1}$ (given $p_{2}(\mathbf{e}$ ) and $\mathbf{e}$ ), the pricing decision $p_{1}(\mathbf{e})$ is uniquely determined by the first-order condition

$$
p_{1}(\mathbf{e})-\frac{\sigma}{1-D_{1}(\mathbf{p}(\mathbf{e}))}-c\left(e_{1}\right)+\left[U_{1}\left(\mathbf{e}^{1+}\right)-U_{1}(\mathbf{e})\right]+\Upsilon\left(p_{2}(\mathbf{e})\right)\left[U_{1}(\mathbf{e})-U_{1}\left(\mathbf{e}^{2+}\right)\right]=0
$$

where $\mathbf{p}(\mathbf{e})=\left(p_{1}(\mathbf{e}), p_{2}(\mathbf{e})\right)$ and

$$
\Upsilon\left(p_{2}(\mathbf{e})\right)=\frac{D_{2}(\mathbf{p}(\mathbf{e}))}{1-D_{1}(\mathbf{p}(\mathbf{e}))}=\frac{\exp \left(-\frac{p_{2}(\mathbf{e})}{\sigma}\right)}{\exp \left(-\frac{p_{0}}{\sigma}\right)+\exp \left(-\frac{p_{2}(\mathbf{e})}{\sigma}\right)}
$$

is the probability of firm 2 making a sale conditional on firm 1 not making a sale.

The pricing decision $p_{1}(\mathbf{e})$ impounds two distinct goals beyond static profit $D_{1}(\mathbf{p}(\mathbf{e}))\left(p_{1}(\mathbf{e})-\right.$ $\left.c\left(e_{1}\right)\right)$ : the advantage-building motive $U_{1}\left(\mathbf{e}^{1+}\right)-U_{1}(\mathbf{e})$ and the advantage-denying motive $U_{1}(\mathbf{e})-U_{1}\left(\mathbf{e}^{2+}\right)$. The advantage-building motive is the reward that the firm receives by winning a sale and moving down its learning curve. The advantage-denying motive is the penalty that the firm avoids by preventing its rival from winning the sale and moving down its learning curve. As we show in Besanko et al. (2014), the advantage-building and advantagedenying motives arise in a broad class of dynamic models and together capture the investment role of price.

\subsection{Equilibrium and industry dynamics}

Because the demand and cost specification is symmetric, we restrict ourselves to symmetric Markov perfect equilibria (MPE) in pure strategies of our learning-by-doing model. Exis-

\footnotetext{
${ }^{6}$ See Appendix A for closed-form expressions for $E_{X}\left[X_{1} \mid X_{1} \geq \widehat{X}_{1}\left(\mathbf{e}^{\prime}\right)\right]$ in equation (2) and $E_{S}\left[S_{1} \mid S_{1} \leq \widehat{S}_{1}\left(\mathbf{e}^{\prime}\right)\right]$ in equation (3).
} 
tence follows from the arguments in Doraszelski \& Satterthwaite (2010). In a symmetric equilibrium, the decisions taken by firm 2 in state $\mathbf{e}$ are identical to the decisions taken by firm 1 in state $\left(e_{2}, e_{1}\right)$. More formally, we have $V_{2}(\mathbf{e})=V_{1}\left(e_{2}, e_{1}\right), U_{2}(\mathbf{e})=U_{1}\left(e_{2}, e_{1}\right)$, $p_{2}(\mathbf{e})=p_{1}\left(e_{2}, e_{1}\right)$, and $\phi_{2}(\mathbf{e})=\phi_{1}\left(e_{2}, e_{1}\right)$. It therefore suffices to determine the value and policy functions $\mathbf{V}_{1}, \mathbf{U}_{1}, \mathbf{p}_{1}$, and $\phi_{1}$ of firm 1 .

Despite the restriction to symmetric equilibria, there is a substantial amount of multiplicity (as in Besanko et al. 2010, Besanko et al. 2014). Because the literature offers little guidance regarding equilibrium selection, we make no attempt to do so and thus view all equilibria that arise for a fixed set of primitives as equally likely. In doing, so we take the ex ante perspective of a regulator that over time will confront a sequence of industries but at present has little detailed knowledge about these industries.

To study the evolution of the industry under a particular equilibrium, we use the policy functions $\mathbf{p}_{1}$ and $\phi_{1}$ to construct the matrix of state-to-state transition probabilities that characterizes the Markov process of industry dynamics. From this, we compute the transient distribution over states in period $t, \boldsymbol{\mu}_{t}$, starting from state $(0,0)$ (the empty industry with just the outside good) in period 0 . In line with our ex ante perspective, we have in mind a nascent industry in which two firms have developed new products that can potentially draw customers away from an established product (the outside good) but have not yet brought them to market 7 The typical element $\mu_{t}(\mathbf{e})$ is the probability that the industry is in state e in period $t$. Depending on $t$, the transient distributions can capture short-run or long-run (steady-state) dynamics. We think of period 500 as the long run and, with a slight abuse of notation, denote $\boldsymbol{\mu}_{500}$ by $\boldsymbol{\mu}_{\infty}$. We use the transient distribution in period 500 rather than the limiting (or ergodic) distribution to capture long-run dynamics because the Markov process implied by the equilibrium may have multiple closed communicating classes.

\section{First-best planner, welfare, and deadweight loss}

\subsection{First-best planner}

Our welfare benchmark is a first-best planner who makes pricing, exit, and entry decisions to maximize the expected NPV of total surplus (consumer plus producer surplus) 8 In contrast to the market, the planner centralizes and coordinates decisions across firms as in Bolton \&

\footnotetext{
${ }^{7}$ Starting from state $(0,0)$ "stacks the deck" against finding small deadweight losses by fully recognizing any distortions in the entry process (see Section 4). It is also an interesting setting in its own right as sellers of next-generation products aiming to establish a "footprint" are a pervasive feature of the business landscape, and one where the investment role of price is particularly salient.

${ }^{8}$ Mermelstein, Nocke, Satterthwaite \& Whinston (2014) consider the expected NPV of total surplus and, to a lesser extent, also the expected NPV of consumer surplus as possible objectives of an antitrust authority. We follow them in using the same discount factor for planner and firms.
} 
Farrell (1990). To "stack the deck" against finding small deadweight losses, we assume an omniscient planner that has access to privately known scrap values and setup costs 9

Combining exit and entry decisions, we let $\psi_{1,1}^{F B}\left(\mathbf{e}^{\prime}\right)$ denote the probability that the planner in state $\mathbf{e}^{\prime}$ decides to operate both firms in the subsequent period, $\psi_{1,0}^{F B}\left(\mathbf{e}^{\prime}\right)$ the probability that the planner decides to operate only firm $1, \psi_{0,1}^{F B}\left(\mathbf{e}^{\prime}\right)$ the probability that the planner decides to operate only firm 2 , and $\psi_{0,0}^{F B}\left(\mathbf{e}^{\prime}\right)$ the probability that the planner decides to operate neither firm.

We use $V^{F B}(\mathbf{e})$ to denote the expected NPV of total surplus in state $\mathbf{e}$ at the beginning of the period and $U^{F B}\left(\mathbf{e}^{\prime}\right)$ the expected NPV of total surplus in state $\mathbf{e}^{\prime}$ after pricing decisions but before exit and entry decisions are made. The price-setting phase determines the value function $\mathbf{V}^{F B}$ along with the policy functions $\mathbf{p}_{n}^{F B}$ for $n \in\{1,2\}$; the entry-exit phase determines the value function $\mathbf{U}^{F B}$ along with the policy functions $\boldsymbol{\psi}_{\iota}^{F B}$ for $\iota \in\{0,1\}^{2}$. We refer to $\iota=\left(\iota_{1}, \iota_{2}\right)$ as the operating decisions of the first-best planner. Note that $\sum_{\boldsymbol{\iota} \in\{0,1\}^{2}} \psi_{\iota}^{F B}\left(\mathbf{e}^{\prime}\right)=1$ and that the probability that firm 1 does not operate in state $\mathbf{e}^{\prime}$ is $\phi_{1}^{F B}\left(\mathbf{e}^{\prime}\right)=\sum_{\iota_{2}=0}^{1} \psi_{0, \iota_{2}}^{F B}\left(\mathbf{e}^{\prime}\right)$.

\section{Operating decisions. Define}

$$
U_{\iota}^{F B}\left(\mathbf{e}^{\prime}, \mathbf{X}, \mathbf{S}\right)=\left\{\begin{array}{ccc}
\beta V^{F B}\left(e_{1}^{\prime} \iota_{1}, e_{2}^{\prime} \iota_{2}\right)+X_{1}\left(1-\iota_{1}\right)+X_{2}\left(1-\iota_{2}\right) & \text { if } \quad e_{1}^{\prime} \neq 0, e_{2}^{\prime}>0, \\
\beta V^{F B}\left(\iota_{1}, e_{2}^{\prime} \iota_{2}\right)-S_{1} \iota_{1}+X_{2}\left(1-\iota_{2}\right) & \text { if } \quad e_{1}^{\prime}=0, e_{2}^{\prime}>0, \\
\beta V^{F B}\left(e_{1}^{\prime} \iota_{1}, \iota_{2}\right)+X_{1}\left(1-\iota_{1}\right)-S_{2} \iota_{2} & \text { if } \quad e_{1}^{\prime}>0, e_{2}^{\prime}=0, \\
\beta V^{F B}\left(\iota_{1}, \iota_{2}\right)-S_{1} \iota_{1}-S_{2} \iota_{2} & \text { if } \quad e_{1}^{\prime}=0, e_{2}^{\prime}=0
\end{array}\right.
$$

to be the expected NPV of total surplus in state $\mathbf{e}^{\prime}$ given operating decisions $\iota \in\{0,1\}^{2}$, scrap values $\mathbf{X}=\left(X_{1}, X_{2}\right)$, and setup costs $\mathbf{S}=\left(S_{1}, S_{2}\right)$. Equation (6) distinguishes between firm $n$ actively producing in the current period $\left(e_{n}^{\prime}>0\right)$ and it being inactive $\left(e_{n}^{\prime}=0\right)$. If firm $n$ is active, then the first-best planner receives the scrap value $X_{n}$ upon deciding not to operate it in the subsequent period $\left(\iota_{n}=0\right)$; if firm $n$ is inactive, then the planner incurs the setup cost $S_{n}$ upon deciding to operate it $\left(\iota_{n}=1\right)$. The optimal operating decisions are

$$
U^{F B}\left(\mathbf{e}^{\prime}, \mathbf{X}, \mathbf{S}\right)=\max _{\iota \in\{0,1\}^{2}} U_{\iota}^{F B}\left(\mathbf{e}^{\prime}, \mathbf{X}, \mathbf{S}\right)
$$

with associated operating probabilities

$$
\psi_{\iota}^{F B}\left(\mathbf{e}^{\prime}\right)=E_{\mathbf{X}, \mathbf{S}}\left[1\left[U^{F B}\left(\mathbf{e}^{\prime}, \mathbf{X}, \mathbf{S}\right)=U_{\iota}^{F B}\left(\mathbf{e}^{\prime}, \mathbf{X}, \mathbf{S}\right)\right]\right]
$$

\footnotetext{
${ }^{9}$ As Bolton \& Farrell (1990) discuss, a central authority may often have more limited information.
} 
for $\iota \in\{0,1\}^{2}$. Finally, the Bellman equation in the exit-entry phase is

$$
U^{F B}\left(\mathbf{e}^{\prime}\right)=E_{\mathbf{X}, \mathbf{S}}\left[U^{F B}\left(\mathbf{e}^{\prime}, \mathbf{X}, \mathbf{S}\right)\right]
$$

Pricing decisions. In the price-setting phase, the expected NPV of total surplus is

$$
V^{F B}(\mathbf{e})=\max _{\mathbf{p}} C S(\mathbf{p})+\sum_{n=1}^{2} D_{n}(\mathbf{p})\left(p_{n}-c\left(e_{n}\right)\right)+\sum_{n=0}^{2} D_{n}(\mathbf{p}) U^{F B}\left(\mathbf{e}^{n+}\right),
$$

where the first term

$$
C S(\mathbf{p})=\sigma \ln \left(\sum_{n=0}^{2} \exp \left(\frac{v-p_{n}}{\sigma}\right)\right)=v+\sigma \ln \left(\sum_{n=0}^{2} \exp \left(\frac{-p_{n}}{\sigma}\right)\right)
$$

is consumer surplus and the second term is the static profit of incumbent firms 10 Because the outside good is priced at cost, its profit is zero.

The solution to the maximization problem on the right-hand side of Bellman equation (9) can be shown to exist and to be unique and is given by

$$
p_{n}^{F B}(\mathbf{e})=c\left(e_{n}\right)-\left[U^{F B}\left(\mathbf{e}^{n+}\right)-U^{F B}(\mathbf{e})\right]
$$

for $n \in\{1,2\}$. The pricing decision $p_{n}^{F B}(\mathbf{e})$ reflects the marginal cost of production $c\left(e_{n}\right)$ of incumbent firm $n$ net of the marginal benefit to society of moving the firm down its learning curve.

Solution and industry dynamics. The solution to the first-best planner problem exists and is unique from the contraction mapping theorem. Without loss of generality, we take the solution to be symmetric in that $V^{F B}(\mathbf{e})=V^{F B}\left(e_{2}, e_{1}\right), U^{F B}(\mathbf{e})=U^{F B}\left(e_{2}, e_{1}\right), p_{1}^{F B}(\mathbf{e})=$ $p_{2}^{F B}\left(e_{2}, e_{1}\right)$, and $\psi_{\iota}^{F B}(\mathbf{e})=\psi_{\iota_{2}, \iota_{1}}^{F B}\left(e_{2}, e_{1}\right)$ for $\iota \in\{0,1\}^{2}$.

We again use the policy functions to construct the matrix of state-to-state transition probabilities that characterizes the Markov process of industry dynamics and compute the transient distribution over states in period $t, \boldsymbol{\mu}_{t}^{F B}$, starting from state $(0,0)$ in period 0.

\subsection{Welfare and deadweight loss}

To capture both short-run and long-run dynamics, our welfare metric is the expected NPV of total surplus. Under a particular equilibrium, total surplus in state $\mathbf{e}$ is the sum of consumer

\footnotetext{
${ }^{10}$ If firm $n$ is inactive, then we again set its price to infinity so that $D_{n}(\mathbf{p})=0$ and its contribution to $C S(\mathbf{p})$ is zero.
} 
and producer surplus:

$$
T S(\mathbf{e})=C S(\mathbf{e})+P S(\mathbf{e}),
$$

where, with a slight abuse of notation, we denote $C S(\mathbf{p}(\mathbf{e}))$ by $C S(\mathbf{e})$, and $P S(\mathbf{e})$ includes the static profit $\Pi(\mathbf{e})=\sum_{n=1}^{2} D_{n}(\mathbf{p}(\mathbf{e}))\left(p_{n}(\mathbf{e})-c\left(e_{n}\right)\right)$ of incumbent firms as well as their expected scrap values and the expected setup costs of potential entrants 11 The expected NPV of total surplus is

$$
T S_{\beta}=\sum_{t=0}^{\infty} \beta^{t} \sum_{\mathbf{e}} \mu_{t}(\mathbf{e}) T S(\mathbf{e}),
$$

where, recall, $\mu_{t}(\mathbf{e})$ is the probability that the industry is in state $\mathbf{e}$ in period $t$.

Under the first-best planner solution, we define the expected NPV of total surplus $T S_{\beta}^{F B}$ analogously. By construction, $T S_{\beta}^{F B}=V^{F B}(0,0)$. The deadweight loss arising in equilibrium therefore is

$$
D W L_{\beta}=T S_{\beta}^{F B}-T S_{\beta}
$$

Because $D W L_{\beta}$ is measured in arbitrary monetary units, we normalize it to better gauge its size and to make it more readily comparable across parameterizations. While it seems natural to express $D W L_{\beta}$ as a percentage of $T S_{\beta}^{F B}$, in our learning-by-doing model both $T S_{\beta}^{F B}$ and $T S_{\beta}$ vary linearly with gross utility $v$ (because consumer surplus does; see equation (10) ). Because $v$ cancels out of $D W L_{\beta}$, we can therefore choose $v$ to make $D W L_{\beta}$ any desired percentage of $T S_{\beta}^{F B}$. Note that the chosen value does not affect the behavior of industry participants in any way.

To avoid this issue, we normalize $D W L_{\beta}$ by the maximum value added by the industry:

$$
V A_{\beta}=T S_{\beta}^{F B}-T S_{\beta}^{\varnothing},
$$

where $T S_{\beta}^{\varnothing}=\frac{v-p_{0}}{1-\beta}$ is the expected NPV of total surplus if the industry remains empty forever with just the outside good. $V A_{\beta}$ can be interpreted as a bound on the contribution of the inside goods to the expected NPV of total surplus. Similar to $D W L_{\beta}, V A_{\beta}$ does not depend on $v$. We henceforth refer to $\frac{D W L_{\beta}}{V A_{\beta}}$ as the relative deadweight loss.

\section{Is dynamic competition necessarily fully efficient?}

In contrast to rent-seeking models, firms in our learning-by-doing model jostle for competitive advantage by pricing aggressively rather than by engaging in socially wasteful activities. To the extent that rents can be efficiently transferred from firms to consumers, one may thus conjecture that dynamic competition is necessarily fully efficient. This conjecture, however,

\footnotetext{
${ }^{11}$ See Appendix A for the expression for $P S(\mathbf{e})$ and its counterpart $P S^{F B}(\mathbf{e})$ under the first-best planner solution.
} 
overlooks that dynamic competition extends beyond pricing into exit and entry. Even if pricing is efficient, exit and entry may not be. Distortions in exit and entry can take the form of over-exit (too much or early exit), under-exit (too little or late exit), over-entry (too much or early entry), under-entry (too little or late entry), and cost-inefficient exit where the lower-cost firm exits the industry while higher-cost firm does not.

We highlight distortions in exit and entry and demonstrate that dynamic competition is not necessarily fully efficient in an analytically tractable special case of our model with a two-step learning curve, homogeneous goods, and mixed exit and entry strategies:

\section{Assumption 1 (Two-step learning curve)}

1. $M=m=2$;

2. $\sigma=0$;

3. $\Delta_{X}=\Delta_{S}=0$.

Because goods are homogeneous by part (2) of Assumption 1, the firm that sets the lowest price makes the sale. Moreover, aggregate demand for the inside goods is inelastic at prices below $p_{0}$. There are therefore no distortions in pricing.

To rule out uninteresting scenarios we further assume:

\section{Assumption 2 (Parameter restrictions)}
1. $p_{0} \geq \kappa$;
2. $\bar{S}>\bar{X} \geq 0$;
3. $\beta\left(p_{0}-\kappa+\frac{\beta}{1-\beta}\left(p_{0}-\rho \kappa\right)\right)>\bar{S}$.

By part (1) of Assumption 2, the marginal cost of the outside good $p_{0}=c_{0}$ is at least as high as the marginal cost $c(1)=\kappa$ of an incumbent firm at the top of its learning curve. By part (2), the setup cost is positive and partially sunk and the scrap value is nonnegative. By part (3), operating a single firm forever is socially beneficial.

The first-best planner solution is straightforward. Because goods are homogeneous and product variety is not socially beneficial, the planner operates the industry as a natural monopoly. In state $(0,0)$ in period 0 , the planner decides to operate a single firm (say firm 1 ) in the subsequent period. In state $(1,0)$ in period 1 , firm 1 charges any price below $p_{0}$, makes the sale, and moves down its learning curve. The industry remains in state $(2,0)$ in period $t \geq 2$ and firm 1 again makes the sale. The expected NPV of total surplus is thus 12

$T S_{\beta}^{F B}=v-p_{0}+\beta(v-\kappa)+\frac{\beta^{2}}{1-\beta}(v-\rho \kappa)-\bar{S}=\frac{v-p_{0}}{1-\beta}+\beta\left(p_{0}-\kappa+\frac{\beta}{1-\beta}\left(p_{0}-\rho \kappa\right)\right)-\bar{S}$,

\footnotetext{
${ }^{12}$ The term $v-p_{0}$ arises because the consumer purchases the outside good in state $(0,0)$.
} 
and the maximum value added by the industry is

$$
V A_{\beta}=\beta\left(p_{0}-\kappa+\frac{\beta}{1-\beta}\left(p_{0}-\rho \kappa\right)\right)-\bar{S} .
$$

In the Online Appendix, we provide further details on the first-best planner solution and the equilibria mentioned hereafter.

Proposition 1 (Two-step learning curve) Under Assumptions 1 and 2 , there exists the equilibrium shown in Table 1. The deadweight loss is

$$
D W L_{\beta}=\frac{\phi_{1}(0,0)(1-\beta)}{1-\beta \phi_{1}(0,0)^{2}} V A_{\beta}+\frac{\left(1-\phi_{1}(0,0)\right)^{2}}{1-\beta \phi_{1}(0,0)^{2}}(\bar{S}-\beta \bar{X})
$$

and the relative deadweight loss is

$$
\frac{D W L_{\beta}}{V A_{\beta}}=\frac{\phi_{1}(0,0)-\beta \phi_{1}(0,0)^{2}}{1-\beta \phi_{1}(0,0)^{2}}
$$

Moreover, $\frac{d\left(1-\phi_{1}(0,0)^{2}\right)}{d \rho}<0$ and $\frac{d\left(D W L_{\beta} / V A_{\beta}\right)}{d \rho}>0$ : as learning economies strengthen, the probability $1-\phi_{1}(0,0)^{2}$ that the industry "takes off" increases and the relative deadweight loss $\frac{D W L_{\beta}}{V A_{\beta}}$ decreases.

The deadweight loss arises because the entry process is decentralized and uncoordinated. The industry can therefore suffer from over-entry and under-entry. To illustrate, we sketch out the evolution of the industry in the equilibrium shown in Table 1. In state $(0,0)$ in period 0 , a single firm enters the industry with probability $2\left(1-\phi_{1}(0,0)\right) \phi_{1}(0,0)$, both firms enter with probability $\left(1-\phi_{1}(0,0)\right)^{2}$, and no firms enter with probability $\phi_{1}(0,0)^{2}$. The industry continues to evolve as follows:

- Case 1. If a single firm (say firm 1 ) enters, then in state $(1,0)$ in period 1 it charges a price just below the price of the outside good $p_{0}$, makes the sale, and moves down its learning curve. In state $(2,0)$ firm 1 remains in the industry $\left(\phi_{1}(2,0)=0\right)$ and firm 2 does not enter $\left(\phi_{1}(0,2)=1\right)$. The industry remains in state $(2,0)$ in period $t \geq 2$, and firm 1 again makes the sale.

- Case 2: Over-entry. If both firms enter, then in state $(1,1)$ in period 1 they charge a price less than static marginal cost $\kappa$. One of the firms (say firm 1) makes the sale and moves down its learning curve. In state $(2,1)$, the leader (firm 1 ) remains in the industry $\left(\phi_{1}(2,1)=0\right)$ and the follower (firm 2) exits $\left(\phi_{1}(1,2)=1\right)$. The industry moves to - and remains in - state $(2,0)$ in period $t \geq 2$. Note that pricing in state 


\begin{tabular}{|c|c|c|c|c|}
\hline $\mathbf{e}$ & $p_{1}(\mathbf{e})$ & $\phi_{1}(\mathbf{e})$ & $V_{1}(\mathbf{e})$ & $U_{1}(\mathbf{e})$ \\
\hline$(0,0)$ & $\infty$ & $\frac{\overline{\bar{S}}-\beta \bar{X}}{\beta\left(p_{0}-\kappa+\frac{\beta}{1-\beta}\left(p_{0}-\rho \kappa\right)\right)-\beta \bar{X}}$ & - & 0 \\
\hline$(0,1)$ & $\infty$ & 1 & - & 0 \\
\hline$(0,2)$ & $\infty$ & 1 & - & 0 \\
\hline$(1,0)$ & $p_{0}^{-}$ & 0 & $p_{0}-\kappa+\frac{\beta}{1-\beta}\left(p_{0}-\rho \kappa\right)$ & $\beta\left(p_{0}-\kappa+\frac{\beta}{1-\beta}\left(p_{0}-\rho \kappa\right)\right)$ \\
\hline$(1,1)$ & $\kappa-\left(\frac{\beta}{1-\beta}\left(p_{0}-\rho \kappa\right)-\bar{X}\right)$ & $\frac{(1-\beta) \bar{X}}{\beta\left(p_{0}-\kappa+\frac{\beta}{1-\beta}\left(p_{0}-\rho \kappa\right)\right)-\beta \bar{X}}$ & $\bar{X}$ & $\bar{X}$ \\
\hline$(1,2)$ & $\kappa$ & 1 & $\bar{X}$ & $\bar{X}$ \\
\hline$(2,0)$ & $p_{0}^{-}$ & 0 & $\frac{p_{0}-\rho \kappa}{1-\beta}$ & $\frac{\beta}{1-\beta}\left(p_{0}-\rho \kappa\right)$ \\
\hline$(2,1)$ & $\kappa^{-}$ & 0 & $(1-\rho) \kappa+\frac{\beta}{1-\beta}\left(p_{0}-\rho \kappa\right)$ & $\frac{\beta}{1-\beta}\left(p_{0}-\rho \kappa\right)$ \\
\hline$(2,2)$ & $\rho \kappa$ & $\frac{(1-\beta) \bar{X}}{\frac{\beta}{1-\beta}\left(p_{0}-\rho \kappa\right)-\beta \bar{X}}$ & $\bar{X}$ & $\bar{X}$ \\
\hline
\end{tabular}

Table 1: Equilibrium. Two-step learning curve. In column labelled $p_{1}(\mathbf{e})$, superscript - indicates that firm 1 charges just below the price stated.

\begin{tabular}{c|c|c|c|c}
\hline $\mathbf{e}$ & $p_{1}(\mathbf{e})$ & $\phi_{1}(\mathbf{e})$ & $V_{1}(\mathbf{e})$ & $U_{1}(\mathbf{e})$ \\
\hline$(0,0)$ & $\infty$ & $\frac{\bar{S}-\beta \bar{X}}{\beta\left(p_{0}-\kappa+\frac{\beta}{1-\beta}\left(p_{0}-\rho \kappa\right)\right)-\beta \bar{X}}$ & 0 \\
$(0,1)$ & $\infty$ & 1 & - & 0 \\
$(0,2)$ & $\infty$ & 0 & - & 0 \\
$(1,0)$ & $p_{0}^{-}$ & $p_{0}-\kappa+\frac{\beta}{1-\beta}\left(p_{0}-\rho \kappa\right)$ & $\beta\left(p_{0}-\kappa+\frac{\beta}{1-\beta}\left(p_{0}-\rho \kappa\right)\right)$ \\
$(1,1)$ & $\kappa$ & $\frac{(1-\beta) \bar{X}}{\beta\left(p_{0}-\kappa+\frac{\beta}{1-\beta}\left(p_{0}-\rho \kappa\right)\right)-\beta \bar{X}}$ & $\bar{X}$ \\
$(1,2)$ & $\kappa$ & $\frac{(1-\beta) \bar{X}-\beta(1-\rho) \kappa}{\beta\left(p_{0}-\kappa+\frac{\beta}{1-\beta}\left(p_{0}-\rho \kappa\right)\right)-\beta \bar{X}}$ & 0 & $\bar{X}$ \\
$(2,0)$ & $p_{0}^{-}$ & $\frac{(1-\beta) \bar{X}}{1-\beta}$ & $\frac{\beta}{1-\beta}\left(p_{0}-\rho \kappa\right)$ \\
$(2,1)$ & $\kappa^{-}$ & $\frac{\beta}{\beta\left(p_{0}-\kappa+\frac{\beta}{1-\beta}\left(p_{0}-\rho \kappa\right)\right)-\beta \bar{X}}$ & $(1-\rho) \kappa+\bar{X}$ & $\bar{X}$ \\
$(2,2)$ & $\rho \kappa$ & $\frac{(1-\beta) \bar{X}}{\frac{\beta}{1-\beta}\left(p_{0}-\rho \kappa\right)-\beta \bar{X}}$ & $\bar{X}$ & $\bar{X}$ \\
\hline
\end{tabular}

Table 2: Equilibrium with cost-inefficient exit. Two-step learning curve. In column labelled $p_{1}(\mathbf{e})$, superscript - indicates that firm 1 charges just below the price stated. 
$(1,1)$ is so aggressive that both firms incur a loss of $-\left(\frac{\beta}{1-\beta}\left(p_{0}-\rho \kappa\right)-\bar{X}\right)$ that fully dissipates any future gains from monopolizing the industry.

- Case 3: Under-entry. If no firm enters, then the above process repeats itself in state $(0,0)$ in period 1.

In short, the intuition that dynamic competition is necessarily fully efficient is incomplete. In the equilibrium shown in Table 1, while the industry evolves towards the monopolistic structure that the first-best planner operates, this may happen slowly over time due to either over-entry or under-entry 13 Wasteful duplication and delay (Bolton \& Farrell 1990) are both integral parts of the equilibrium 14

The equilibrium shown in Table 1 further entails a war of attrition (Maynard Smith 1974, Tirole 1988, Bulow \& Klemperer 1999) in state $(2,2)$, although state $(2,2)$ is off the equilibrium path starting from state $(0,0)$. The war of attrition arises because a firm is better off staying in the industry if its rival exits but worse off if its rival stays. As a firm hopes to outlast its rival, it clings to the industry. The resulting non-operating probability is $\phi_{1}(2,2)=\frac{(1-\beta) \bar{X}}{\frac{\beta}{1-\beta}\left(p_{0}-\rho \kappa\right)-\beta \bar{X}} \in(0,1)$, whereas the first-best planner ceases to operate one of the two firms in state $(2,2)$. Because the exit process is decentralized and uncoordinated, the industry can suffer not only from over-exit but also from under-exit 15

Under Assumptions 1 and 2, there exist two other equilibria. Even in this special case of our model, multiple equilibria are endemic. These equilibria differ from the one in Table 1 only in the exit-entry phase in state $(1,0)$. In the first equilibrium, the incumbent firm exits the industry and the potential entrant enters $\left(\phi_{1}(1,0)=1\right.$ and $\left.\phi_{1}(0,1)=0\right)$; in the second equilibrium, the incumbent firm and the potential entrant play mixed strategies $\left(\phi_{1}(1,0)=\frac{\bar{S}-\beta \bar{X}}{\beta\left(p_{0}-\kappa+\frac{\beta}{1-\beta}\left(p_{0}-\rho \kappa\right)\right)-\beta \bar{X}} \in(0,1)\right.$ and $\left.\phi_{1}(0,1)=\frac{(1-\beta) \bar{X}}{\beta\left(p_{0}-\kappa+\frac{\beta}{1-\beta}\left(p_{0}-\rho \kappa\right)\right)-\beta \bar{X}} \in(0,1)\right)$. Because the exit-entry phase in state $(1,0)$ is off the equilibrium path starting from state $(0,0)$, however, these equilibria give rise to the deadweight loss in equations (13) and (14).

Finally, under the additional assumption that $\bar{X} \geq \frac{\beta}{1-\beta} \kappa(1-\rho)$, there exists the equilibrium, shown in Table 2, with cost-inefficient exit. In state $(2,1)$, the incumbent firms play

\footnotetext{
${ }^{13}$ The first term in equation (13) is due to under-entry and the "discount factor" $\frac{\phi_{1}(0,0)(1-\beta)}{1-\beta \phi_{1}(0,0)^{2}}$ captures the stochastic length of time over which under-entry may occur; the second term is due to over-entry and the "discount factor" $\frac{\left(1-\phi_{1}(0,0)\right)^{2}}{1-\beta \phi_{1}(0,0)^{2}}$ captures the stochastic length of time over which over-entry can occur after potentially many periods of under-entry.

${ }^{14}$ Treating the entry process as decentralized and uncoordinated by focusing on symmetric equilibria "stacks the deck" against finding small deadweight losses. While asymmetric or correlated equilibria can avoid wasteful duplication and delay, as Bolton \& Farrell (1990) discuss it is far from clear how the firms will "find" one of these equilibria without some process of explicit coordination.

${ }^{15}$ Coordination failures in exit and entry may be exacerbated if there are more than two firms (Cabral 1993, Vettas 1998). Intuitively, the support of the binomial distribution becomes more spread out with more draws.
} 
mixed strategies. Hence, the lower-cost firm may exit the industry while the higher-cost firm does not. Note that this equilibrium entails cost-inefficient exit not only in an ex post sense but also in an ex ante sense as the lower-cost firm exits the industry with higher probability than the higher-cost firm $\left(\phi_{1}(2,1)>\phi_{1}(1,2)\right)$.

\section{$5 \quad$ Numerical analysis and equilibrium}

The special case of a two-step learning curve relies on extreme values of key parameters. In doing so, it assumes away a meaningful role for product variety and competition from the outside good that can be a source of distortions in pricing. Unfortunately, analytic tractability rapidly declines beyond the two-step learning curve. Moreover, while theoretical analysis has enabled us to establish that dynamic competition is not necessarily fully efficient, theoretical analysis is ill-suited to answer the question of how efficient dynamic competition is. We therefore turn to numerical analysis.

\subsection{Computation and parameterization}

To thoroughly explore the equilibrium correspondence and search for multiple equilibria in a systematic fashion, we use the homotopy or path-following method in Besanko et al. (2010) 16 We caution that the homotopy algorithm cannot be guaranteed to find all equilibria and refer to reader to Besanko et al. (2010) and Borkovsky, Doraszelski \& Kryukov (2010, 2012) for additional discussion. We solve the first-best planner problem using value function iteration combined with quasi-Monte Carlo integration (Halton sequences of length 10,000) to evaluate the operating probabilities in equation (7) and the Bellman equation (8).

Our learning-by-doing model has four key parameters: the progress ratio $\rho \in[0,1]$, the degree of product differentiation $\sigma>0$, the price of the outside good $p_{0}=c_{0} \geq 0$, and the expected scrap value $\bar{X} \in\left[-\Delta_{X}, \bar{S}+\Delta_{S}+\Delta_{X}\right] 17$ To explore how the equilibria vary with these parameters, we compute six two-dimensional slices through the equilibrium correspondence along $(\rho, \sigma),\left(\rho, p_{0}\right),(\rho, \bar{X}),\left(\sigma, p_{0}\right),(\sigma, \bar{X})$, and $\left(\bar{X}, p_{0}\right)$. We choose sufficiently large upper bounds for $\sigma$ and $p_{0}$ so that beyond them "things don't change much anymore." Back-of-the-envelope calculations yield $\sigma \leq 10$ and $p_{0} \leq 20$. Throughout we hold the remaining parameters fixed at the values in the second column of Table 3 . While this baseline parameterization is not intended to be representative of any particular industry, it is neither entirely unrepresentative nor extreme.

\footnotetext{
${ }^{16}$ The equilibrium correspondence is $\mathbf{H}^{-1}(\boldsymbol{\omega})=\{\mathbf{x} \mid \mathbf{H}(\mathbf{x}, \boldsymbol{\omega})=0\}$, where $\boldsymbol{\omega}=\left(\rho, \sigma, p_{0}, \bar{X}, \ldots\right)$ are the parameters of the model, $\mathbf{x}=\left(\mathbf{V}_{1}, \mathbf{U}_{1}, \mathbf{p}_{1}, \phi_{1}\right)$ are the value and policy functions, and $\mathbf{H}(\mathbf{x}, \boldsymbol{\omega})=0$ are the Bellman equations and optimality conditions that define an equilibrium.

${ }^{17}$ The bounds on $\bar{X}$ follow from the economic requirement that upon exit a firm's assets are valuable $\left(X_{n} \geq 0\right)$ but that their value is limited by the firm's initial outlay at the time of its inception $\left(X_{n} \leq S_{n}\right)$.
} 


\begin{tabular}{l|c|l}
\hline parameter & value & grid \\
\hline maximum stock of know-how $M$ & 30 & \\
cost at top of learning curve $\kappa$ & 10 & \\
bottom of learning curve $m$ & 15 & \\
progress ratio $\rho$ & 0.75 & $\rho \in\{0,0.05, \ldots, 1\}$ \\
gross utility $v$ & 10 & \\
product differentiation $\sigma$ & 1 & $\sigma \in\{0.2,0.3, \ldots, 1,1.3,1.6,2$, \\
& & $2.5,3.2,4,5,6.3,7.9,10\}$ \\
price of outside good $p_{0}$ & 10 & $p_{0} \in\{0,1, \ldots, 20\}$ \\
scrap value $\bar{X}, \Delta_{X}$ & $1.5,1.5$ & $\bar{X} \in\{-1.5,-1, \ldots, 7.5\}$ \\
setup cost $\bar{S}, \Delta_{S}$ & $4.5,1.5$ & \\
discount factor $\beta$ & 0.95 & \\
\hline
\end{tabular}

Table 3: Baseline parameterization and grid points.

An industry without firms is unlikely to attract the attention of a regulator. We therefore exclude extreme parameterizations for which the industry is not viable in the sense that the probability $1-\phi_{1}(0,0)^{2}$ that the industry "takes off" is below 0.01. Unsurprisingly, these parameterizations involve a highly attractive outside good with $p_{0}<5$.

Due to the large number of parameterizations and multiplicity of equilibria, we require a way to summarize them. In a first step, we average an outcome of interest over the equilibria at a parameterization. This random sampling is in line with our decision to refrain from equilibrium selection and ensures that parameterizations with many equilibria carry the same weight as parameterizations with few equilibria.

In a second step, we randomly sample parameterizations. To make this practical, we represent a two-dimensional slice through the equilibrium correspondence with a grid of values for the parameters spanning the slice. The third column of Table 3 lists the grid points we use for the four key parameters. We mostly use uniformly spaced grid points, except for $\sigma>1$, where the grid points approximate a log scale in order to explore very high degrees of product differentiation. We associate each point in a two-dimensional grid with the corresponding average over equilibria. We then pool the points on the six slices through the equilibrium correspondence along $(\rho, \sigma),\left(\rho, p_{0}\right),(\rho, \bar{X}),\left(\sigma, p_{0}\right),(\sigma, \bar{X})$, and $\left(\bar{X}, p_{0}\right)$ and obtain the distribution of the outcome of interest.

\subsection{Equilibrium and first-best planner solution}

To illustrate the types of behavior that can emerge in our learning-by-doing model, we examine the equilibria that arise at the baseline parameterization in Table 3 . For two of these three equilibria Figure 1 shows the pricing decision of firm 1, the non-operating probability of firm 2, and the time path of the probability distribution over industry structures (empty, 
monopoly, and duopoly) 18

The upper panels of Figure 1 1exemplify what we call an aggressive equilibrium in Besanko et al. (2014). The pricing decision in the upper left panel exhibits a deep well in state $(1,1)$ with $p_{1}(1,1)=-34.78$. A well is a preemption battle where firms vie to be the first to move down from the top of their learning curves. Such a battle is likely to ensue because $\phi_{1}(0,0)=0.04$ implies that the probability that both firms enter the industry in period 0 is 0.92 . After the industry has emerged from the preemption battle in state $(1,1)$, the leader (say firm 1 ) continues to price aggressively $\left(p_{1}(2,1)=0.08\right)$. Indeed, the pricing decision exhibits a deep trench along the $e_{1}$-axis with $p_{1}\left(e_{1}, 1\right)$ ranging from 0.08 to 1.24 for $e_{1} \in\{2, \ldots, 30\} 19$ A trench is a price war that the leader wages against the follower. We can think of a trench is an endogenous mobility barrier in the sense of Caves \& Porter (1977). In the trench the follower (firm 2) exits the industry with a positive probability of $\phi_{2}\left(e_{1}, 1\right)=0.22$ for $e_{1} \in\{2, \ldots, 30\}$ as the upper middle panel shows. The follower remains in this exit zone as long as it does not win a sale. Once the follower exits, the leader raises its price and the industry becomes an entrenched monopoly 20 This sequence of events resembles conventional notions of predatory pricing 21 The industry may also evolve into a mature duopoly if the follower manages to crash through the mobility barrier by winning a sale but, as the upper right panel of Figure 1 shows, this is far less likely than an entrenched monopoly.

The lower panels of Figure 1] are typical for what we call an accommodative equilibrium in Besanko et al. (2014). There is a shallow well in state $(1,1)$ with $p_{1}(1,1)=5.05$ as the lower left panel shows. A preemption battle is again likely to ensue because $\phi_{1}(0,0)=0.05$ implies that the probability that both firms enter the industry in period 0 is 0.91 . After the industry has emerged from the preemption battle in state $(1,1)$, the leader enjoys a competitive advantage over the follower. Without mobility barriers in the form of trenches, however, this advantage is temporary and the industry evolves into a mature duopoly as the lower right panel shows.

First-best planner solution. Figure 2 is analogous to Figure 1 and illustrates the firstbest planner solution. In state $(0,0)$ in period 0 , the planner decides to operate a single firm (say firm 1) in the subsequent period since $\psi_{1,0}^{F B}(0,0)=\psi_{0,1}^{F B}(0,0)=0.5$. In period $t \geq 1$,

\footnotetext{
${ }^{18}$ The third equilibrium is essentially intermediate between the two shown in Figure 1 ,

${ }^{19}$ Because prices are strategic complements, there is also a shallow trench along the $e_{2}$-axis with $p_{1}\left(1, e_{2}\right)$ ranging from 3.63 to 4.90 for $e_{2} \in\{2, \ldots, 30\}$.

${ }^{20}$ While our model allows for re-entry, whether it actually occurs depends on how a potential entrant assesses its prospects in the industry. In this particular equilibrium, $\phi_{2}\left(e_{1}, 0\right)=1.00$ for $e_{1} \in\{2, \ldots, 30\}$, so that the potential entrant does not enter if the incumbent firm has moved down from the top of its learning curve.

${ }^{21}$ In Besanko et al. (2014) we formalize the notion of predatory pricing and disentangle it from mere competition for efficiency on a learning curve.
} 

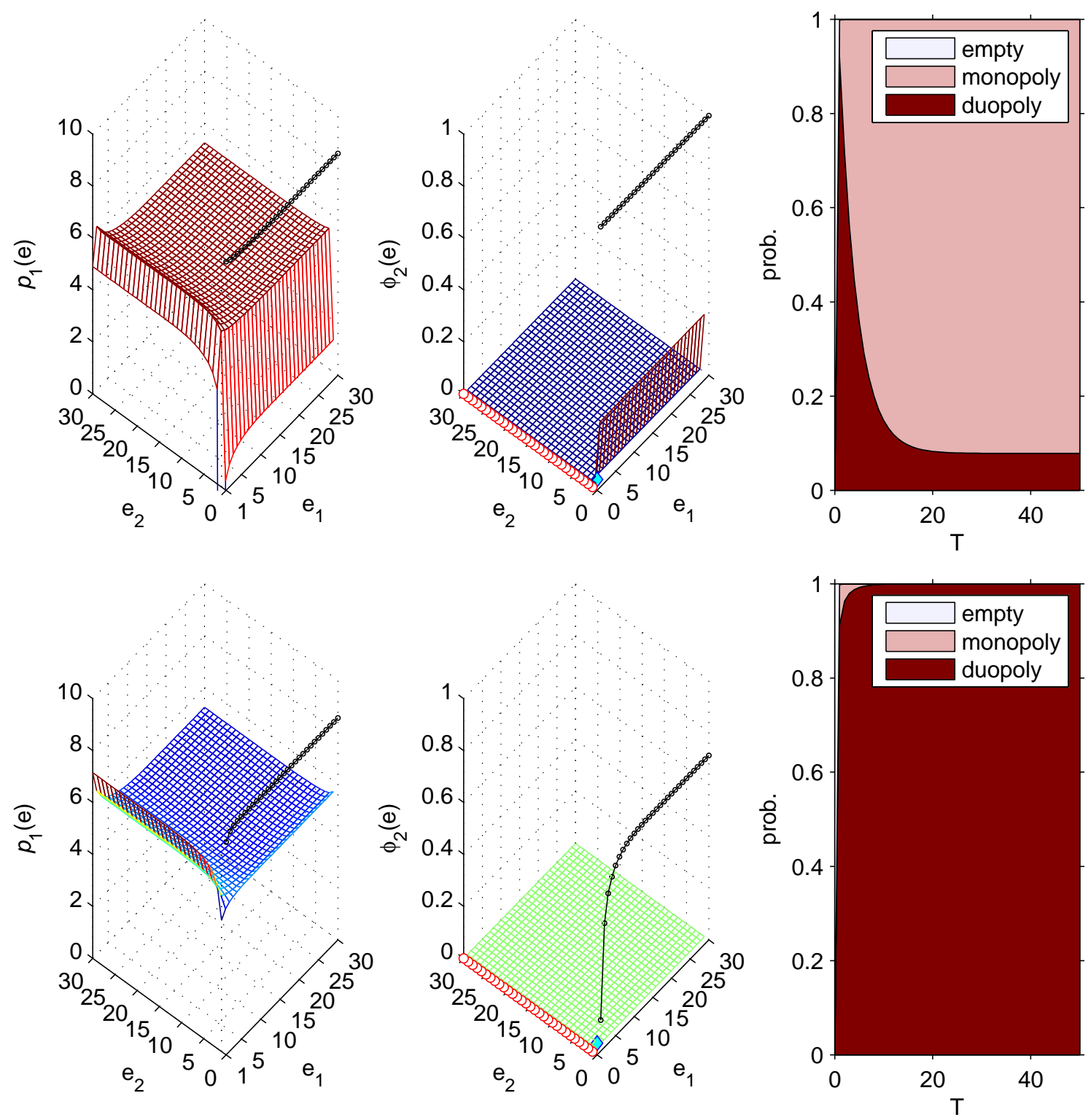

Figure 1: Aggressive (upper panels) and accommodative (lower panels) equilibrium. Pricing decision of firm 1 (left panels), non-operating probability of firm 2 (middle panels), and time path of probability distribution over industry structures (right panels). Dots above the surface in left panels are $p_{1}\left(e_{1}, 0\right)$ for $e_{1}>0$ and dots in middle panels are $\phi_{2}\left(0, e_{2}\right)$ for $e_{2}>0$ and $\phi_{2}\left(e_{1}, 0\right)$ for $e_{1} \geq 0$. Baseline parameterization. 

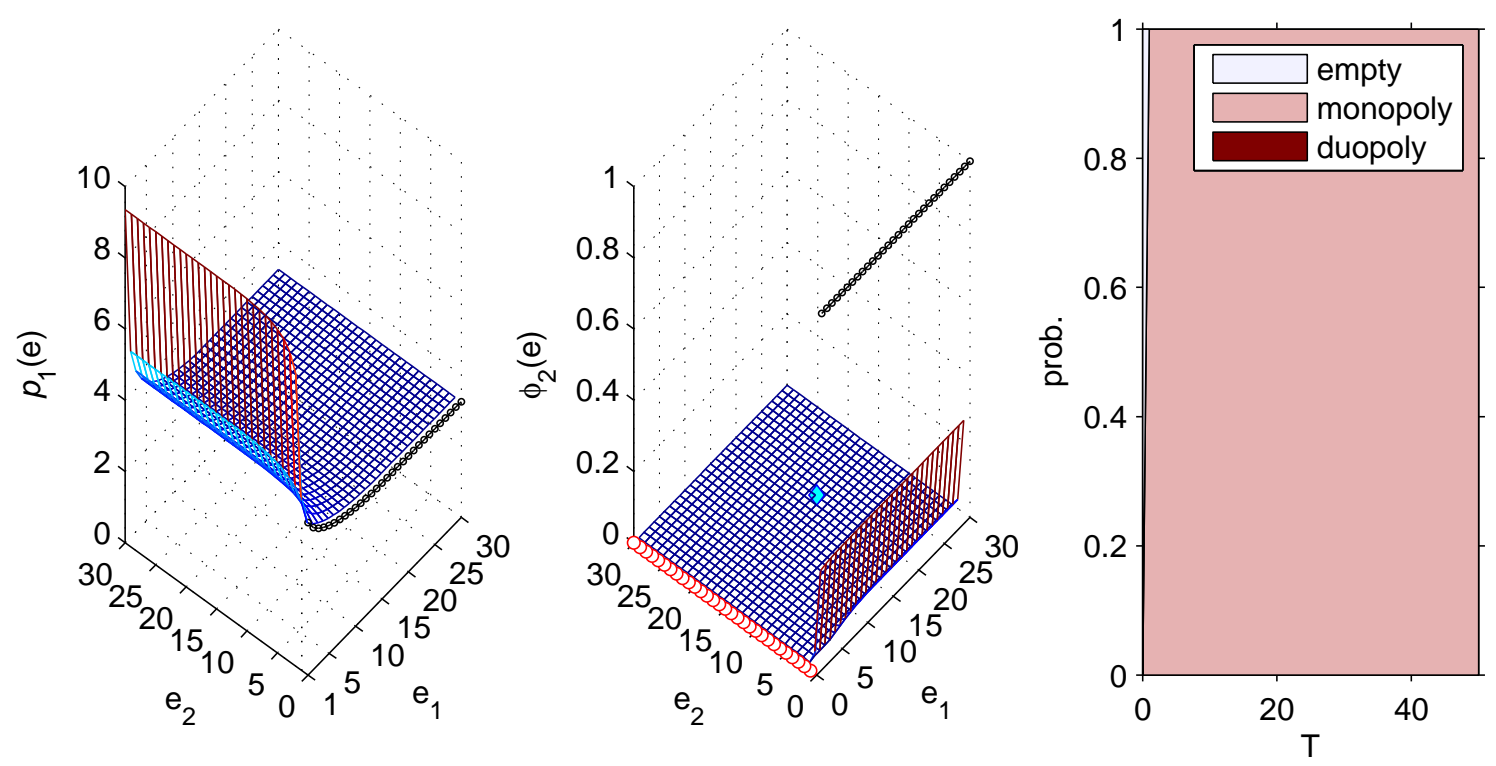

Figure 2: First-best planner solution. Pricing decision of firm 1 (left panel), non-operating probability of firm 2 (middle panel), and time path of probability distribution over industry structures (right panel). Dots beside the surface in left panel are $p_{1}\left(e_{1}, 0\right)$ for $e_{1}>0$ and dots in middle panel are $\phi_{2}\left(0, e_{2}\right)$ for $e_{2}>0$ and $\phi_{2}\left(e_{1}, 0\right)$ for $e_{1} \geq 0$. Baseline parameterization.

the planner marches firm 1 down its learning curve. As the left panel shows, $p_{1}^{F B}(\mathbf{e})=3.25$ if $e_{1} \in\{15, \ldots, 30\}$ so that at the bottom of its learning curve firm 1 charges a price equal to marginal cost. In short, the planner operates the industry as a natural monopoly.

As the middle panel shows, there is an exit zone somewhat similar to the one in the aggressive equilibrium. Although state $(1,1)$ is off the equilibrium path starting from state $(0,0), \psi_{1,0}^{F B}(1,1)=\psi_{0,1}^{F B}(1,1)=0.04$ implies that if both firms are at the top of their learning curves, then the first-best planner ceases to operate one of them with probability 0.07 to receive the scrap value. On the other hand, if both firms are part of the way down their learning curves, then $\psi_{1,1}^{F B}(\mathbf{e})=1$ for $\mathbf{e} \geq(3,3)$ implies that the planner continues to operate both to secure the social benefit of product variety.

Outside the baseline parameterization in Table 3, the first-best planner does not necessarily operate the industry as a natural monopoly. In particular, if the degree of product differentiation is sufficiently large, then the planner immediately decides to operate both firms and continues to do so as they move down their learning curves.

Industry structure, conduct, and performance. To succinctly describe an equilibrium and compare it to the first-best planner solution, we use several metrics of industry 


\begin{tabular}{l|r|r|r|r}
\hline & $\begin{array}{r}\text { aggr. } \\
\text { eqbm. }\end{array}$ & $\begin{array}{r}\text { accom. } \\
\text { eqbm. }\end{array}$ & $\begin{array}{r}\text { planner } \\
\text { solution }\end{array}$ & $\begin{array}{c}\text { counter- } \\
\text { factual }\end{array}$ \\
\hline structure: & 1.92 & 1.91 & 1.00 & 2.00 \\
expected short-run number of firms $N_{1}$ & 1.08 & 2.00 & 1.00 & 2.00 \\
expected long-run number of firms $N_{\infty}$ & & & & \\
conduct: & 8.28 & 5.24 & 3.25 & 5.24 \\
expected long-run average price $\bar{p}_{\infty}$ & 19.09 & 37.54 & 15.02 & 53.91 \\
expected time to maturity $T^{m}$ & & & & \\
performance: & 93.87 & 103.29 & 131.66 & 56.88 \\
expected NPV of consumer surplus $C S_{\beta}$ & 96.02 & 105.45 & 110.45 & 92.02 \\
expected NPV of total surplus $T S_{\beta}$ & 14.43 & 5.01 & - & 18.43 \\
deadweight loss $D W L_{\beta}$ & $13.06 \%$ & $4.54 \%$ & - & $16.69 \%$ \\
relative deadweight loss $\frac{D W L_{\beta}}{V A_{\beta}}$ &
\end{tabular}

Table 4: Industry structure, conduct, and performance. Aggressive and accommodate equilibrium, first-best planner solution, and static non-cooperative pricing counterfactual. Baseline parameterization.

structure, conduct, and performance 22 The second, third, and fourth columns of Table 4 show these metrics for the aggressive and accommodative equilibrium and the planner solution. We discuss the fifth column of Table 4 in Section 6.1.

The expected short-run number of firms $N_{1}$ is just above 1.90 in both equilibria, compared to $N_{1}^{F B}=1.00$ in the first-best planner solution. In the aggressive equilibrium, the expected long-run number of firms $N_{\infty}$ is 1.08 , quite close to the planner solution. In contrast, in the accommodative equilibrium, $N_{\infty}=2.00$. The aggressive equilibrium therefore mainly involves over-entry and the accommodative equilibrium involves both over-entry and underexit.

The expected long-run average price $\bar{p}_{\infty}^{F B}=3.25$ in the first-best planner solution is equal to marginal cost at the bottom of the learning curve. It is much higher in both equilibria. In the aggressive equilibrium, in particular, $\bar{p}_{\infty}=8.28$ reflects the fact that the industry most likely evolves into an entrenched monopoly.

The expected time to maturity $T^{m}$ is the expected time until the industry first becomes either a mature monopoly or a mature duopoly; it measures the speed at which firms move down their learning curves. Learning economies are exhausted fastest in the first-best planner solution with $T^{m, F B}=15.02$, followed by the aggressive equilibrium with $T^{m}=19.10$ and the accommodative equilibrium with $T^{m}=37.50$. This large gap arises because sales are split between the inside goods in the accommodative equilibrium, as well as at least initially with the outside good.

\footnotetext{
${ }^{22}$ See Appendix A for formal definitions.
} 
As the industry is substantially more likely to be monopolized in the aggressive equilibrium than in the accommodative equilibrium, the expected NPV of consumer surplus $C S_{\beta}$ is lower, as is the expected NPV of total surplus $T S_{\beta}$. Consequently, the deadweight loss $D W L_{\beta}$ is higher in the aggressive equilibrium than in the accommodative equilibrium. However, the relative deadweight loss $\frac{D W L_{\beta}}{V A_{\beta}}$ seems modest, with $13.06 \%$ of the maximum value added by the industry in the aggressive equilibrium and $4.54 \%$ in the accommodative equilibrium.

\section{Does dynamic competition lead to low deadweight loss?}

The relative deadweight loss $\frac{D W L_{\beta}}{V A_{\beta}}$ is modest more generally. Summarizing a large number

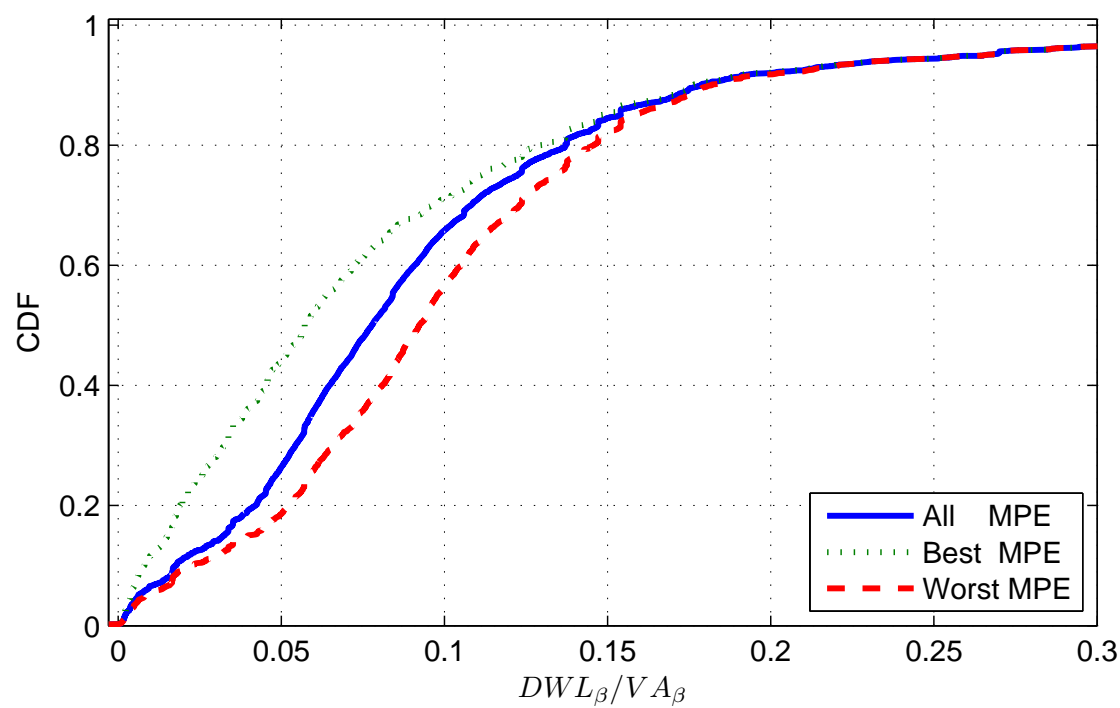

Figure 3: Distribution of relative deadweight loss $\frac{D W L_{\beta}}{V A_{\beta}}$. All equilibria (solid line), best equilibrium (dotted line), and worst equilibrium (dashed line). Parameterizations and equilibria within parameterizations weighted equally.

of parameterizations and equilibria, Figure 3 shows the cumulative distribution function $(\mathrm{CDF})$ of $\frac{D W L_{\beta}}{V A_{\beta}}$ as a solid line. Result 1 highlights some findings:

Result 1 The relative deadweight loss $\frac{D W L_{\beta}}{V A_{\beta}}$ is less than $0.05,0.1$, and 0.2 in 26.40\%, $65.83 \%$, and 92.03\% of parameterizations, respectively. The median of $\frac{D W L_{\beta}}{V A_{\beta}}$ is $0.077 \%$.

There is a large relative deadweight loss $\frac{D W L_{\beta}}{V A_{\beta}}$ for a small number of parameterizations. Under these parameterizations, the industry almost fails to take off (in the sense that 1 $\left.\phi_{1}(0,0)^{2} \approx 0.01\right)$ because the outside good is highly attractive. Near this "cusp of viability" 
the contribution of the inside goods to the expected NPV of total surplus is small and thus $V A_{\beta} \approx 0$.

Recall that we average over equilibria at a given parameterization to obtain the distribution of $\frac{D W L_{\beta}}{V A_{\beta}}$. To look behind these averages, we consider the best equilibrium with the highest value of $T S_{\beta}$ at a given parameterization as well as the worst equilibrium with the lowest value of $T S_{\beta}$. Figure 3 shows the resulting distributions of $\frac{D W L_{\beta}}{V A_{\beta}}$ using a dotted line for the best equilibrium and a dashed line for the worst equilibrium, and Result 2 summarizes:

Result 2 (1) For the best equilibrium, the relative deadweight loss $\frac{D W L_{\beta}}{V A_{\beta}}$ is less than 0.05 , 0.1 , and 0.2 in 44.25\%, 71.11\%, and 92.10\% of parameterizations, respectively. The median

of $\frac{D W L_{\beta}}{V A_{\beta}}$ is 0.0571 . (2) For the worst equilibrium, the relative deadweight loss $\frac{D W L_{\beta}}{V A_{\beta}}$ is less than $0.05,0.1$, and 0.2 in 18.67\%, 56.40\%, and $91.80 \%$ of parameterizations, respectively. The median of $\frac{D W L_{\beta}}{V A_{\beta}}$ is 0.0922.

Hence, even in the worst equilibria the relative deadweight loss $\frac{D W L_{\beta}}{V A_{\beta}}$ is modest for a wide range of parameterizations.

In Appendix C we offer formal definitions of aggressive and accommodative equilibria and link them to the worst, respectively, best equilibria. Although this link is far from perfect, to facilitate the exposition and build intuition, in what follows we associate the best equilibrium with an accommodative equilibrium and the worst equilibrium - to the extent that it differs from the best equilibrium - with an aggressive equilibrium. If the equilibrium is unique, then we associate it with an accommodative equilibrium.

\subsection{Deadweight loss in perspective: static non-cooperative pricing coun- terfactual}

Is a relative deadweight loss $\frac{D W L_{\beta}}{V A_{\beta}}$ of $10 \%$ of the maximum value added by the industry "small" and a relative deadweight loss of 30\% "large"? To put these percentages in perspective, we show that the deadweight loss is lower than expected in view of the traditional role of price as affecting current profit but not the evolution of the industry. To this end, we shut down the investment role of price. In the price-setting phase, incumbent firm 1 is thus left to maximize static profit

$$
\max _{p_{1}} D_{1}\left(p_{1}, p_{2}^{S N}(\mathbf{e})\right)\left(p_{1}-c\left(e_{1}\right)\right)
$$


and the pricing decision $p_{1}^{S N}(\mathbf{e})$ in this static non-cooperative pricing counterfactual is uniquely determined by the first-order condition

$$
p_{1}^{S N}(\mathbf{e})=c\left(e_{1}\right)+\frac{\sigma}{1-D_{1}\left(\mathbf{p}^{S N}(\mathbf{e})\right)},
$$

where $\mathbf{p}^{S N}(\mathbf{e})=\left(p_{1}^{S N}(\mathbf{e}), p_{2}^{S N}(\mathbf{e})\right)$. The expected NPV of incumbent firm 1 is

$$
\begin{gathered}
V_{1}^{S N}(\mathbf{e})=D_{1}\left(\mathbf{p}^{S N}(\mathbf{e})\right)\left(p_{1}^{S N}(\mathbf{e})-c\left(e_{1}\right)\right) \\
+U_{1}^{S N}(\mathbf{e})+\sum_{n=1}^{2} D_{n}\left(\mathbf{p}^{S N}(\mathbf{e})\right)\left[U_{1}^{S N}\left(\mathbf{e}^{n+}\right)-U_{1}^{S N}(\mathbf{e})\right]
\end{gathered}
$$

and, in contrast to the pricing decision, accounts for the impact of a sale on the value of continued play. Finally, the exit-entry phase is as described in Section 2.123 Our computations always led to a unique solution.

The fifth column of Table 4 shows our metrics for industry structure, conduct, and performance for the static non-cooperative pricing counterfactual at the baseline parameterization. Similar to the accommodative equilibrium, the counterfactual involves both over-entry and under-exit $\left(N_{1}^{S N}=2.00\right.$ and $\left.N_{\infty}^{S N}=2.00\right)$. Learning economies are exhausted even more slowly than in the accommodative equilibrium $\left(T^{m, S N}=53.91>37.45=T^{m}\right)$ because firms ignore the investment role of price in making their pricing decisions. The deadweight loss $D W L_{\beta}$ increases more than threefold relative to the accommodative equilibrium and by more than a quarter relative to the aggressive equilibrium.

The investment role of price is socially beneficial more generally. Figure 4 shows the distribution of the deadweight loss ratio $\frac{D W L_{\beta}^{S N}}{D W L_{\beta}}$. Note that $\frac{D W L_{\beta}^{S N}}{D W L_{\beta}}$ is independent of our normalization by $V A_{\beta}$. Result 3 summarizes:

Result $3 D W L_{\beta}^{S N}$ is at least as large as $D W L_{\beta}$ in $80.11 \%$ of parameterizations, at least twice as large in $44.01 \%$ of parameterizations, and at least five times as large in $13.66 \%$ of parameterizations. The median of $\frac{D W L_{\beta}^{S N}}{D W L_{\beta}}$ is 1.7842 .

$D W L_{\beta}^{S N}$ is smaller than $D W L_{\beta}$ in a number of parameterizations that mostly involve an unattractive outside good $\left(p_{0} \geq 15\right)$. The outside good constrains pricing decisions and profitability much more in a monopolistic than in a duopolistic industry. A less attractive outside good lifts this constraint and sharpens the incentive to monopolize the industry in equilibrium. But if firms ignore the investment role of price in the static non-cooperative pricing counterfactual, then a duopolistic industry with a lower deadweight loss emerges.

\footnotetext{
${ }^{23}$ Our static non-cooperative pricing counterfactual loosely corresponds to the version of the war of attrition presented in Tirole (1988), with the addition of learning-by-doing and product differentiation.
} 


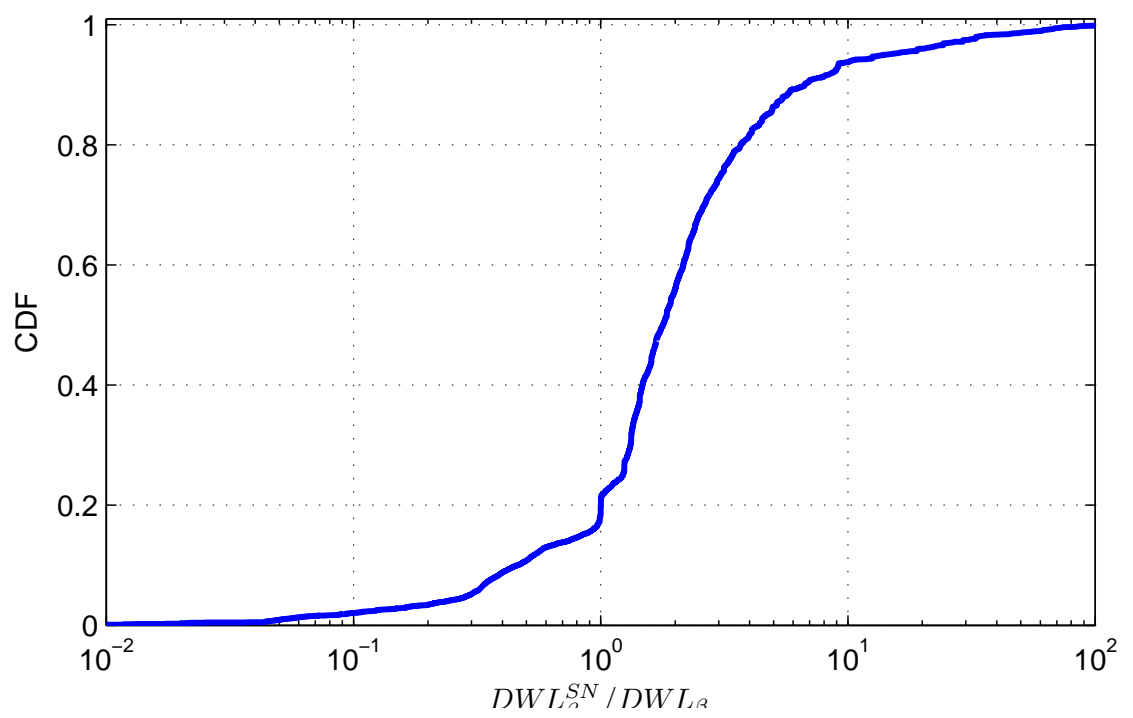

Figure 4: Distribution of deadweight loss ratio $\frac{D W L_{\beta}^{S N}}{D W L_{\beta}}$. Log scale. Parameterizations and equilibria within parameterizations weighted equally.

Generally speaking, we conclude that dynamic competition leads to low deadweight loss. The deadweight loss is low not only relative to the maximum value added by the industry, it is also smaller than the deadweight loss that arises if firms ignore the investment role of price 24 Put differently, the investment role of price is by and large socially beneficial. The static non-cooperative pricing counterfactual also shows that a low deadweight loss is almost certainly not hardwired into the primitives of our learning-by-doing model. Instead, there is something in the nature of the investment role of price and dynamic competition that in equilibrium leads to low deadweight loss.

\subsection{Differences between equilibria and first-best planner solution}

Dynamic competition leads to low deadweight loss despite distortions in pricing, exit, and entry. Indeed, as we next show, there are typically substantial differences between the equilibria and the first-best planner solution. Paradoxically, the best equilibrium can differ even more from the planner solution than the worst equilibrium.

Recall that too low prices cause deadweight loss from overproduction, just as too high prices cause deadweight loss from underproduction. To illustrate that the equilibria involve prices that are too low, we first define $1\left[p_{1}(\mathbf{e})<c\left(e_{1}\right)\right.$ for some $\left.\mathbf{e} \in\{1, \ldots, M\} \times\{0, \ldots, M\}\right]$

\footnotetext{
${ }^{24}$ It is also smaller than the deadweight loss that arises if firms collude in their pricing, exit, and entry decisions. For the baseline parameterization in Table 3 the relative deadweight loss $\frac{D W L_{\beta}^{C O}}{V A_{\beta}}$ in the collusive solution is $14.32 \%$ of the maximum value added by the industry. In the Online Appendix, we provide further details on the collusive solution.
} 
to indicate that a price is below the marginal cost of production in at least one state. Second, we define $1\left[p_{1}(\mathbf{e})<p_{1}^{F B}(\mathbf{e})\right.$ for some $\left.\mathbf{e} \in\{1, \ldots, M\} \times\{0, \ldots, M\}\right]$ to indicate that a price is below the first-best planner solution in some state. Result 4 summarizes the distribution of these indicators:

Result 4 (1) $p_{1}(\mathbf{e})<c\left(e_{1}\right)$ for some $\mathbf{e} \in\{1, \ldots, M\} \times\{0, \ldots, M\}$ in all equilibria in $79.75 \%$ of parameterizations. (2) $p_{1}(\mathbf{e})<p_{1}^{F B}(\mathbf{e})$ for some $\mathbf{e} \in\{1, \ldots, M\} \times\{0, \ldots, M\}$ in all equilibria in $55.70 \%$ of parameterizations.

We caution that the states with too low prices are not necessarily on the equilibrium path starting from state $(0,0)$.

We next turn from pricing to exit and entry and compare the expected short-run and long-run number of firms between the equilibria and the first-best planner solution. Figure 5 shows the distribution of $N_{1}-N_{1}^{F B}$ as a solid line and Result 5 highlights some findings:

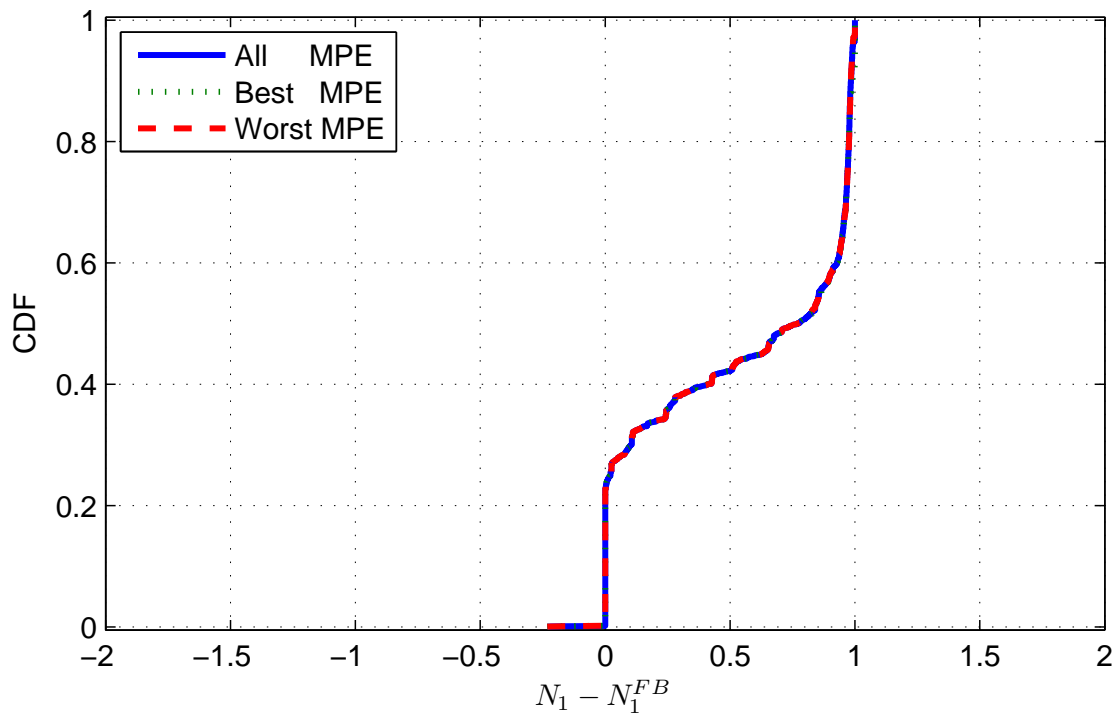

Figure 5: Distribution of $N_{1}-N_{1}^{F B}$. All equilibria (solid line), best equilibrium (dotted line), and worst equilibrium (dashed line). Parameterizations and equilibria within parameterizations weighted equally.

Result $5 N_{1}$ is larger than $N_{1}^{F B}$ in $78.78 \%$ of parameterizations and smaller than $N_{1}^{F B}$ in $0.15 \%$ of parameterizations. The median of $N_{1}-N_{1}^{F B}$ is 0.773325

Thus, the equilibria typically have too many firms in the short run, consistent with overentry. They very rarely have too few firms in the short run. Figure 5 also breaks out the

\footnotetext{
${ }^{25}$ In stating Result [5] we take $N_{1}$ to be equal to $N_{1}^{F B}$ if $\left|N_{1}-N_{1}^{F B}\right|<0.0001$ to account for the limited precision of our computations. We proceed analogously in stating Result 6 .
} 
best equilibrium as a dotted line and the worst equilibrium as a dashed line. Similar to our examples in Section [5.2, there is no discernible difference between the best and the worst equilibrium.

Figure 6 shows the distribution of $N_{\infty}-N_{\infty}^{F B}$ as a solid line and breaks out the best equilibrium as a dotted line and the worst equilibrium as a dashed line. Result 6 summarizes:

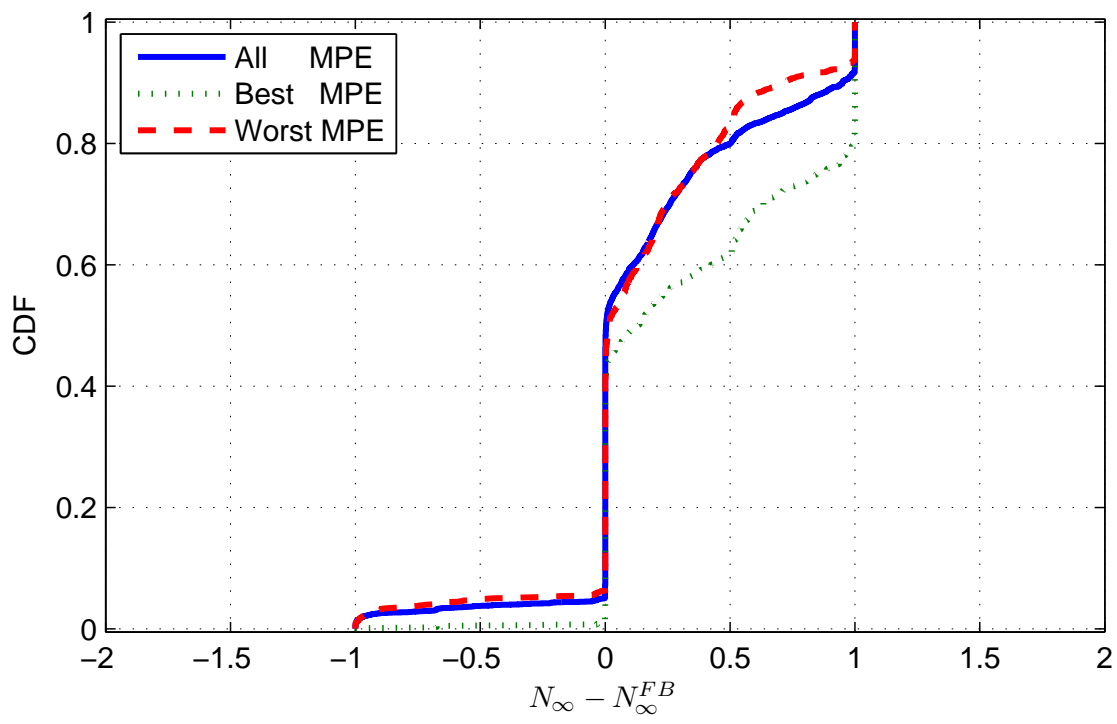

Figure 6: Distribution $N_{\infty}-N_{\infty}^{F B}$. All equilibria (solid line), best equilibrium (dotted line), and worst equilibrium (dashed line). Parameterizations and equilibria within parameterizations weighted equally.

Result 6 (1) $N_{\infty}$ is larger than $N_{\infty}^{F B}$ in $53.77 \%$ of parameterizations and smaller than $N_{\infty}^{F B}$ in $5.07 \%$ of parameterizations. The median of $N_{\infty}-N_{\infty}^{F B}$ is 0.0038 . (2) For the best equilibrium, $N_{\infty}$ is larger than $N_{\infty}^{F B}$ in 59.21\% of parameterizations and smaller than $N_{\infty}^{F B}$ in $0.94 \%$ of parameterization. The median of $N_{\infty}-N_{\infty}^{F B}$ is 0.132\%. (3) For the worst equilibrium, $N_{\infty}$ is larger than $N_{\infty}^{F B}$ in $58.77 \%$ of parameterizations and smaller than $N_{\infty}^{F B}$ in $6.27 \%$ of parameterizations. The median of $N_{\infty}-N_{\infty}^{F B}$ is $0.016 \%$.

Thus, the equilibria regularly have too many firms in the long run, consistent with underexit. This tendency is exacerbated in the best equilibrium. The equilibria very rarely have too few firms in the long run.

We finally turn to the speed at which firms move down their learning curves. Recall that the expected time to maturity $T^{m}$ depends on both the number of incumbent firms and their pricing decisions. Figure 7 shows the distribution of $T^{m}-T^{m, F B}$ as a solid line and 
breaks out the best equilibrium as a dotted line and the worst equilibrium as a dashed line. Result 7 summarizes:

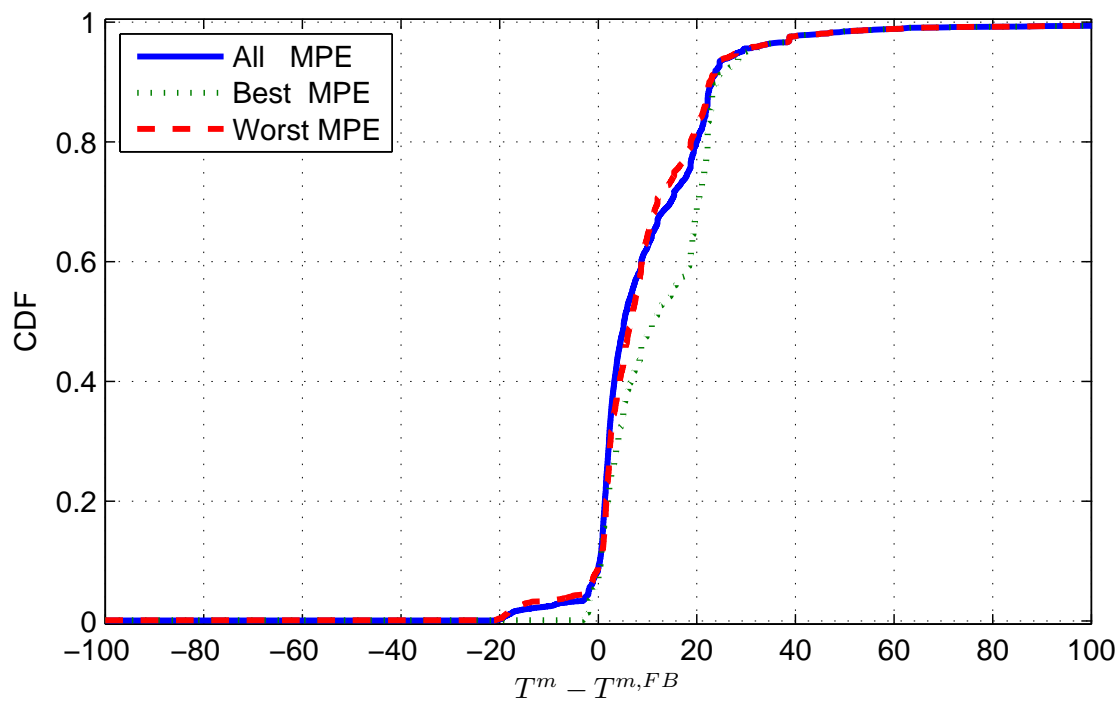

Figure 7: Distribution of $T^{m}-T^{m, F B}$. All equilibria (solid line), best equilibrium (dotted line), and worst equilibrium (dashed line). Parameterizations and equilibria within parameterizations weighted equally.

Result 7 (1) $T^{m}$ is larger than $T^{m, F B}$ in $90.69 \%$ of parameterizations and smaller than $T^{m, F B}$ in $8.35 \%$ of parameterizations 26 The median of $T^{m}-T^{m, F B}$ is 5.2502. (2) For the best equilibrium, $T^{m}$ is larger than $T^{m, F B}$ in $91.97 \%$ of parameterizations and smaller than $T^{m, F B}$ in $6.46 \%$ of parameterization. The median of $T^{m}-T^{m, F B}$ is 11.3581. (3) For the worst equilibrium, $T^{m}$ is larger than $T^{m, F B}$ in $90.49 \%$ of parameterizations and smaller than $T^{m, F B}$ in $8.69 \%$ of parameterizations. The median of $T^{m}-T^{m, F B}$ is 6.6216 .

The speed of learning in the equilibria is generally too slow. Moreover, the best equilibrium exhausts learning economies even more slowly than the worst equilibrium. This is because pricing is initially less aggressive and more firms split sales in an accommodative equilibrium than in an aggressive equilibrium.

\section{Why does dynamic competition lead to low deadweight loss?}

Section 6 leaves us with a puzzle. Dynamic competition leads to low deadweight loss, but this is not because the equilibrium resembles the first-best planner solution. On the contrary, the

\footnotetext{
${ }^{26}$ In stating Result 7 we take $T^{m}$ to be equal to $T^{m, F B}$ if $\left|T^{m}-T^{m, F B}\right|<0.1$.
} 
best equilibrium can differ even more from the planner solution than the worst equilibrium.

\subsection{Decomposition}

To better understand why dynamic competition leads to low deadweight loss, we quantify the importance of three factors that together make up deadweight loss: pricing conduct, exit and entry conduct, and market structure. We accordingly decompose the deadweight loss in equation (12) as

$$
D W L_{\beta}=T S_{\beta}^{F B}-T S_{\beta}=D W L_{\beta}^{P R}+D W L_{\beta}^{E E}+D W L_{\beta}^{M S}
$$

where

$$
\begin{gathered}
D W L_{\beta}^{P R}=\sum_{t=0}^{\infty} \beta^{t} \sum_{\mathbf{e}} \mu_{t}(\mathbf{e})\left[C S^{F B}(\mathbf{e})+\Pi^{F B}(\mathbf{e})-(C S(\mathbf{e})+\Pi(\mathbf{e}))\right] \\
D W L_{\beta}^{E E}=\sum_{t=0}^{\infty} \beta^{t} \sum_{\mathbf{e}} \mu_{t}(\mathbf{e})\left[P S^{F B}(\mathbf{e})-\Pi^{F B}(\mathbf{e})-(P S(\mathbf{e})-\Pi(\mathbf{e}))\right] \\
D W L_{\beta}^{M S}=\sum_{t=0}^{\infty} \beta^{t} \sum_{\mathbf{e}}\left[\mu_{t}^{F B}(\mathbf{e})-\mu_{t}(\mathbf{e})\right] T S^{F B}(\mathbf{e}),
\end{gathered}
$$

and, recall, $\Pi(\mathbf{e})=\sum_{n=1}^{2} D_{n}(\mathbf{p}(\mathbf{e}))\left(p_{n}(\mathbf{e})-c\left(e_{n}\right)\right) . \Pi^{F B}(\mathbf{e})$ is defined analogously.

$C S(\mathbf{e})+\Pi(\mathbf{e})$ is the sum of consumer surplus and the static profit of the incumbent firms in state e. The pricing distortion $D W L_{\beta}^{P R}$ in equation (15) is the incremental deadweight loss due to state-wise differences in pricing conduct between the equilibrium and the first-best planner solution 27

$P S(\mathbf{e})-\Pi(\mathbf{e})$ is the difference of producer surplus and the static profit of the incumbent firms in state e and thus the part of producer surplus that accounts for scrap values and setup costs. The exit and entry distortion $D W L_{\beta}^{E E}$ in equation (16) is therefore the incremental deadweight loss due to state-wise differences in exit and entry conduct between the equilibrium and the first-best planner solution. Expected inflows from scrap values in state e contribute positively to $P S(\mathbf{e})-\Pi(\mathbf{e})$ and expected outflows from setup costs negatively. A positive value of $D W L_{\beta}^{E E}$ thus reflects a tendency for over-entry or under-exit relative to the first-best planner solution while a negative value reflects a tendency for under-entry or over-exit.

The market structure distortion $D W L_{\beta}^{M S}$ in equation (17) is the incremental deadweight loss due to differences in the evolution of the industry over time between the equilibrium

\footnotetext{
${ }^{27}$ In our model, there is no distinction between price and quantity distortions. As demand is invertible, consumer surplus in equation (10) can be written as a function of quantities rather than prices.
} 
and the first-best planner solution. Recall that the state e completely describes the number of incumbent firms - and therefore the extent of product variety-along with their cost positions. A negative value of $D W L_{\beta}^{M S}$ therefore indicates that the equilibrium puts more weight on more favorable market structures with higher values of $T S^{F B}(\mathbf{e})$ than the planner solution; a positive value indicates the reverse. Note that $T S^{F B}(\mathbf{e})$ is high if firms' cost positions in state $\mathbf{e}$ in relation to the price of the outside good yield large gains from trade. $T S^{F B}(\mathbf{e})$ is also high if a large number of firms fosters product variety. Perhaps less obviously, $T S^{F B}(\mathbf{e})$ is high if in state e there are too many firms from the perspective of the first-best planner, thus allowing the planner to receive scrap values by ceasing to operate excess firms. Of course, these last two effects of the number of firms are mutually exclusive. The factors contributing to a negative value of $D W L_{\beta}^{M S}$ are therefore over-entry and under-exit as well as fast exploitation of learning economies. The factors contributing to a positive value of $D W L_{\beta}^{M S}$ are under-entry, over-exit, slow exploitation of learning economies, and cost-inefficient exit. Cost-inefficient exit contributes to a positive value of $D W L_{\beta}^{M S}$ in the same way as slow exploitation of learning economies by rendering firms' cost positions less favorable. Table 5 summarizes the distortions that the signs of $D W L_{\beta}^{E E}$ and $D W L_{\beta}^{M S}$ indicate.

\begin{tabular}{l|l|l}
\hline term & \multicolumn{1}{|c|}{ positive } & \multicolumn{1}{|c}{ negative } \\
\hline$D W L_{\beta}^{E E}$ & over-entry, under-exit & under-entry, over-exit \\
$D W L_{\beta}^{M S}$ & $\begin{array}{l}\text { under-entry, over-exit, slow ex- } \\
\text { ploitation of learning economies, } \\
\text { cost-inefficient exit }\end{array}$ & $\begin{array}{l}\text { ploitation of learning economies } \\
\end{array}$ \\
\hline
\end{tabular}

Table 5: Decomposition terms and contributing distortions.

$D W L_{\beta}^{E E}$ and $D W L_{\beta}^{M S}$ can offset each other as they depend on over-entry and under-exit in opposite ways. We therefore define the non-pricing distortion as $D W L_{\beta}^{N P R}=D W L_{\beta}^{E E}+$ $D W L_{\beta}^{M S}$. It reflects (1) the net social loss from a suboptimal number of firms (setup costs net of scrap values net of social benefits of product variety), (2) the gross social loss from a suboptimal exploitation of learning economies, and (3) the gross social loss from costinefficient exit.

Examples. Table 6 illustrates the decomposition for the aggressive and accommodative equilibria at the baseline parameterization. The pricing distortion $D W L_{\beta}^{P R}=10.78$ is the largest part of deadweight loss $D W L_{\beta}=14.43$ in the aggressive equilibrium. It is mainly driven by the high expected long-run average price $\bar{p}_{\infty}=8.28$ (see Table 4) that results as the industry most likely evolves into a mature monopoly. In the accommodative equilibrium, the pricing distortion $D W L_{\beta}^{P R}=2.35$ is a smaller part of deadweight loss $D W L_{\beta}=5.01$ 


\begin{tabular}{l|rrrrr}
\hline & $D W L_{\beta}$ & $D W L_{\beta}^{P R}$ & $D W L_{\beta}^{E E}$ & $D W L_{\beta}^{M S}$ & $D W L_{\beta}^{N P R}$ \\
\hline aggr. eqbm. & 14.43 & 10.78 & 4.67 & -1.01 & 3.66 \\
accom. eqbm. & 5.01 & 2.35 & 7.32 & -4.67 & 2.66 \\
\hline
\end{tabular}

Table 6: Decomposition. Aggressive and accommodative equilibrium. Baseline parameterization.

because the industry evolves into a mature duopoly. Interestingly, $D W L_{\beta}^{P R}$ is small even though the expected long-run average price $\bar{p}_{\infty}=5.24$ is almost two-thirds larger than in the first-best planner solution $\left(\bar{p}_{\infty}^{F B}=3.25\right) 28$

In the accommodative equilibrium, the largest part of deadweight loss $D W L_{\beta}=5.01$ is the exit and entry distortion $D W L_{\beta}^{E E}=7.32$. This reflects both wasteful duplication of setup costs due to over-entry and scrap values that firms forgo in equilibrium due to under-exit. The latter is analogous to the wasteful duplication of per-period, avoidable fixed costs that arises in the standard war of attrition model in Tirole (1988) 29 In contrast, in the aggressive equilibrium $D W L_{\beta}^{E E}=4.67$ is a smaller part of $D W L_{\beta}=14.43$ because the follower is likely to eventually exit the industry and receive the scrap value.

In both equilibria, the market structure distortion $D W L_{\beta}^{M S}$ is negative, indicating that the industry spends more time in favorable market structures than in the first-best planner solution. This is driven by over-entry and under-exit as opposed to fast exploitation of learning economies. Indeed, in both equilibria learning economies are exhausted more slowly $\left(T^{m}=19.10\right.$ and $T^{m}=37.50$, see again Table 4) than in the planner solution $\left(T^{m, F B}=\right.$ 15.02).

As $D W L_{\beta}^{M S}$ partially offsets $D W L_{\beta}^{E E}$, the non-pricing distortion $D W L_{\beta}^{N P R}=3.66$ is much smaller than the pricing distortion $D W L_{\beta}^{P R}=10.78$ in the aggressive equilibrium. In the accommodative equilibrium the non-pricing distortion $D W L_{\beta}^{N P R}=2.66$ is slightly larger than the pricing distortion $D W L_{\beta}^{P R}=2.35$.

General results. These patterns generalize. Summarizing a large number of parameterizations and equilibria, Figure 8 shows the distribution of $\frac{D W L_{\beta}^{P R}}{D W L_{\beta}}, \frac{D W L_{\beta}^{E E}}{D W L_{\beta}}, \frac{D W L_{\beta}^{M S}}{D W L_{\beta}}$, and $\frac{D W L_{\beta}^{N P R}}{D W L_{\beta}}$. We scale each term of the decomposition by $D W L_{\beta}$ to better gauge its size. Result 8 highlights some findings:

\footnotetext{
${ }^{28}$ Dynamic first-best prices $\left(p_{1}^{F B}(\mathbf{e}), p_{2}^{F^{B}}(\mathbf{e})\right)$, in turn, coincide with static first-best prices $\left(c\left(e_{1}\right), c\left(e_{2}\right)\right)$ if $\mathbf{e} \geq(m, m)$.

${ }^{29}$ In the Online Appendix, we establish that our model with scrap values is equivalent to a model with per-period, avoidable fixed costs but without scrap values.
} 


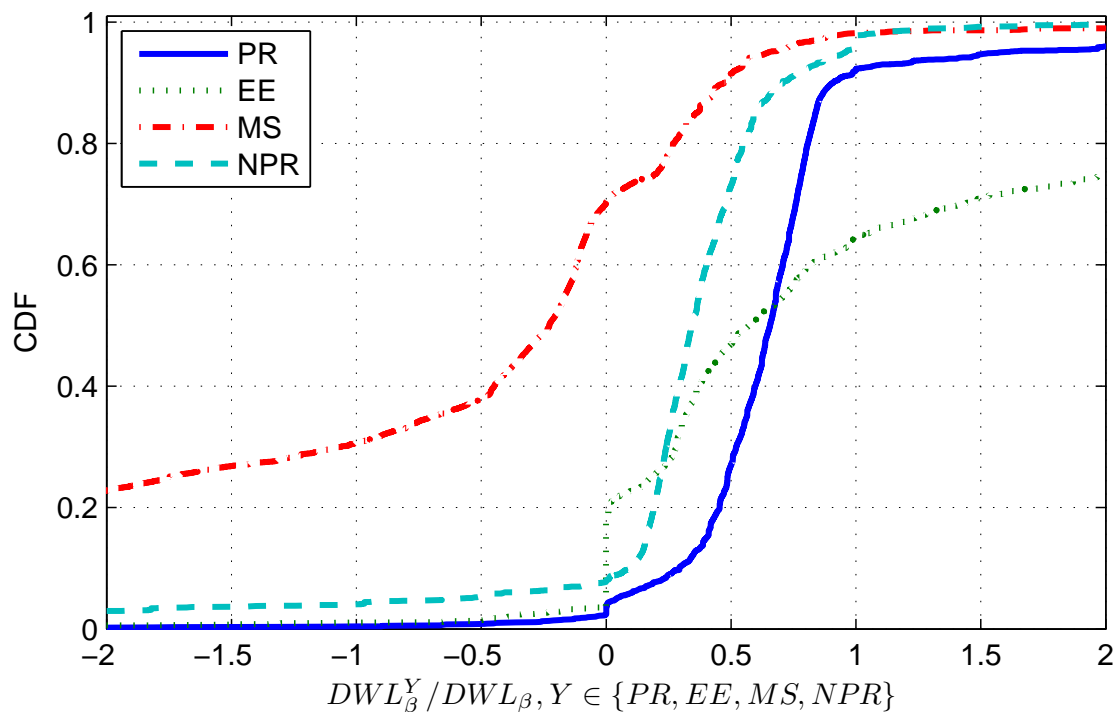

Figure 8: Distribution of $\frac{D W L_{\beta}^{P R}}{D W L_{\beta}}, \frac{D W L_{\beta}^{E E}}{D W L_{\beta}}, \frac{D W L_{\beta}^{M S}}{D W L_{\beta}}$, and $\frac{D W L_{\beta}^{N P R}}{D W L_{\beta}}$. Parameterizations and equilibria within parameterizations weighted equally.

Result 8 (1) The pricing distortion $D W L_{\beta}^{P R}$ is positive in $96.44 \%$ of parameterizations 30 The median of $\frac{D W L_{\beta}^{P R}}{D W L_{\beta}}$ is 0.6565 . (2) The exit and entry distortion $D W L_{\beta}^{E E}$ is positive in $81.26 \%$ of parameterizations. The median of $\frac{D W L_{\beta}^{E E}}{D W L_{\beta}}$ is 0.5728 . (3) The market structure distortion $D W L_{\beta}^{M S}$ is negative in $70.07 \%$ of parameterizations. The median of $\frac{D W L_{\beta}^{M S}}{D W L_{\beta}}$ is -0.2279. (4) The non-pricing distortion $D W L_{\beta}^{N P R}$ is positive in 92.03\% of parameterizations. The median of $\frac{D W L_{\beta}^{N P R}}{D W L_{\beta}}$ is 0.3435 .

$D W L_{\beta}^{E E}$ is typically positive by part (2) of Result 8 because of over-entry and under-exit 31 Also because of over-entry and under-exit, $D W L_{\beta}^{M S}$ is typically negative by part (3), as the speed of learning in the equilibria is generally too slow (see Figure 7 and Result 7) 32 Thus, as highlighted in Result 9, $D W L_{\beta}^{M S}$ typically offsets $D W L_{\beta}^{E E}$ so that $D W L_{\beta}^{N P R}$ is very often smaller than its largest component (in absolute value):

Result $9\left|D W L_{\beta}^{N P R}\right|$ is smaller than $\max \left\{\left|D W L_{\beta}^{E E}\right|,\left|D W L_{\beta}^{M S}\right|\right\}$ in $88.64 \%$ of parameterizations.

\footnotetext{
${ }^{30}$ In stating Result 8 we take $D W L_{\beta}^{P R}$ to be zero if $\left|\frac{D W L_{\beta}^{P R}}{D W L_{\beta}}\right|<0.001$. We proceed analogously for the other terms of the decomposition.

${ }^{31} D W L_{\beta}^{E E}$ is zero in $14.87 \%$ of parameterizations and negative in just $3.87 \%$ of parameterizations (see again footnote 30).

${ }^{32} D W L_{\beta}^{M S}$ can be positive if the degree of product differentiation $\sigma$ is sufficiently large to ensure that the industry evolves into a mature duopoly under the equilibrium and the first-best planner solution. In this case, the positive value of $D W L_{\beta}^{M S}$ reflects mainly the slow exploitation of learning economies.
} 
Parts (1) and (4) of Result 8 show that generally both pricing and non-pricing distortions contribute to deadweight loss. As Result 10 shows, the pricing distortion is often larger than the non-pricing distortion:

Result 10 The pricing distortion $D W L_{\beta}^{P R}$ is larger than the non-pricing distortion $D W L_{\beta}^{N P R}$ in $73.23 \%$ of parameterizations.

Armed with these patterns in the decomposition terms, we delve into the mechanisms through which dynamic competition leads to low deadweight loss. We proceed separately according to type of equilibrium.

\subsection{Why is the best equilibrium so good?}

The deadweight loss in the best equilibrium is small although it often differs greatly from the first-best planner solution. Recall that we associate the best equilibrium with an accommodative equilibrium. To see why the deadweight loss in an accommodative equilibrium is small, recall from Result 10 that the pricing distortion is often larger than the non-pricing distortion. In a first step, we show that the pricing distortion $D W L_{\beta}^{P R}$ is small. In a second step, we argue that the non-pricing distortion $D W L_{\beta}^{N P R}$ is small because of the social benefit of product variety.

Why is the pricing distortion small? At first blush, there appears to be no reason for the pricing distortion in an accommodative equilibrium to be particularly small. At the baseline parameterization, equilibrium prices $\left(p_{1}(\mathbf{e}), p_{2}(\mathbf{e})\right)$ substantially exceed static first-best prices $\left(c\left(e_{1}\right), c\left(e_{2}\right)\right)$ even once the industry becomes a mature duopoly.

Proposition 2, however, bounds the contribution $C S^{F B}(\mathbf{e})+\Pi^{F B}(\mathbf{e})-(C S(\mathbf{e})+\Pi(\mathbf{e}))$ to the pricing distortion $D W L_{\beta}^{P R}$ by the demand for the outside good $D_{0}(\mathbf{p}(\mathbf{e}))$ :

Proposition 2 Consider a symmetric state $\mathbf{e}=(e, e)$, where $e>0$. If $p_{0} \geq \kappa, p_{1}(\mathbf{e})>c(e)$, and $D_{0}(\mathbf{p}(\mathbf{e}))<\frac{1}{2}$, then

$$
C S^{F B}(\mathbf{e})+\Pi^{F B}(\mathbf{e})-(C S(\mathbf{e})+\Pi(\mathbf{e})) \leq \frac{\left(p_{1}(\mathbf{e})-c(e)\right)^{2}}{\sigma} D_{0}(\mathbf{p}(\mathbf{e}))\left(1-D_{0}(\mathbf{p}(\mathbf{e}))\right) .
$$

Note that the bound on the right-hand side of equation (18) approaches zero as the demand for the outside good approaches zero. This often has bite: as the incumbent firms move down their learning curves, they improve their cost positions relative to the price of the outside good and drive the share of the outside good close to zero. Exceptions occur only if learning economies are weak $-\rho$ is close to 1 - or inconsequential because the outside good is highly attractive. 
While the bound on the right-hand side of equation (18) relies on logit demand, the intuition is more general. To a first-order approximation, the deadweight loss due to market power decreases as demand becomes less price elastic (Harberger 1954). With logit demand, a decrease in the price elasticity of aggregate demand for the inside goods is associated with a decrease in the demand for the outside good. With linear demand, the aggregate demand for the inside goods similarly becomes less elastic as their prices - and with them the demand for the outside good - decrease.

Why is the non-pricing distortion small? Recall that the non-pricing distortion $D W L_{\beta}^{N P R}=$ $D W L_{\beta}^{E E}+D W L_{\beta}^{M S}$ reflects the net social loss from a suboptimal number of firms as well as the gross social losses from suboptimal exploitation of learning economies and cost-inefficient exit. Recall, too, that, broadly speaking, in particular accommodative equilibria have too many firms, both in the short run and in the long run, consistent with over-entry and underexit (Results 5, 6, and parts (2) and (3) of Result [). Negative values of $D W L_{\beta}^{M S}$ thus tend to offset positive values of $D W L_{\beta}^{E E}$ (Result 9).

Of course, too many firms give rise to a social loss from the wasteful duplication of setup costs due to over-entry and scrap values that firms forgo in equilibrium due to under-exit. However, there is a "silver lining": too many firms give rise to a social benefit from additional product variety. Because of the social benefit of product variety, the net social loss from too many firms is small. This is especially relevant because accommodative equilibria tend to arise when the degree of product differentiation $\sigma$ is high (see Appendix C). Hence, the social benefit of product variety tends to be large.

Learning economies accentuate the silver lining of additional product variety. Suppose the industry evolves into a mature duopoly in an accommodative equilibrium and into a mature monopoly in the first-best planner solution, and that there is no further exit and entry. Then there exists a period $t^{*}$ such that for period $t \geq t^{*}$, the equilibrium transient distribution $\mu_{t}(\mathbf{e})$ puts all mass on state $\mathbf{e}$, where $\mathbf{e} \geq(m, m)$, and the first-best transient distribution $\mu_{t}^{F B}(\mathbf{e})$ puts all mass on state $\mathbf{e}$, where either $e_{1} \geq m$ and $e_{2}=0$ or $e_{1}=0$ and $e_{2} \geq m$. Because learning economies are exhausted and there is no further exit and entry, we have $T S^{F B}(\mathbf{e})=T S^{F B}(m, m)$ if $\mathbf{e} \geq(m, m)$, and $T S^{F B}(\mathbf{e})=T S^{F B}(m, 0)$ if either $e_{1} \geq m$ and $e_{2}=0$ or $e_{1}=0$ and $e_{2} \geq m$. Moreover, $T S^{F B}(m, m)=C S^{F B}(m, m)$ and $T S^{F B}(m, 0)=C S^{F B}(m, 0)$ because the planner sets static first-best prices. Hence, the market structure distortion $D W L_{\beta}^{M S}$ can be approximated as

$$
\sum_{t=0}^{t^{*}} \beta^{t} \sum_{\mathbf{e}}\left[\mu_{t}^{F B}(\mathbf{e})-\mu_{t}(\mathbf{e})\right] T S^{F B}(\mathbf{e})-\frac{\beta^{t^{*}+1}}{1-\beta}\left[C S^{F B}(m, m)-C S^{F B}(m, 0)\right],
$$

where the last term can be thought of as a reduction in $D W L_{\beta}^{M S}$ - and thus in the non- 
pricing distortion $D W L_{\beta}^{N P R}$ — due to the social benefit of additional product variety. From equation (10) it is straightforward to establish that

$$
\begin{gathered}
C S^{F B}(m, m)-C S^{F B}(m, 0) \\
=\sigma\left(\ln \left(\exp \left(\frac{-p_{0}}{\sigma}\right)+2 \exp \left(\frac{-c(m)}{\sigma}\right)\right)-\ln \left(\exp \left(\frac{-p_{0}}{\sigma}\right)+\exp \left(\frac{-c(m)}{\sigma}\right)\right)\right),
\end{gathered}
$$

where $c(m)=\kappa \rho^{\log _{2} m}$ from equation (1), and

$\frac{d\left(C S^{F B}(m, m)-C S^{F B}(m, 0)\right)}{d \rho}=-\left(2 D_{1}(c(m), c(m))-D_{1}(c(m), \infty)\right) \kappa \rho^{\log _{2} m-1} \log _{2} m<0$,

since $2 D_{1}(c(m), c(m))=\frac{2}{2+\exp \left(-\left(\frac{p_{0}-c(m)}{\sigma}\right)\right)}>\frac{1}{1+\exp \left(-\left(\frac{p_{0}-c(m)}{\sigma}\right)\right)}=D_{1}(c(m), \infty)$. Hence, as learning economies strengthen, the reduction in $D W L_{\beta}^{M S}$ and $D W L_{\beta}^{N P R}$ due to the social benefit of additional product variety increases.

\subsection{Why is the worst equilibrium not so bad?}

Recall that we associate the worst equilibrium with an aggressive equilibrium. To see why the deadweight loss in an aggressive equilibrium is small (albeit not as small as in the best equilibrium), we show in a first step that the pricing distortion $D W L_{\beta}^{P R}$ is small. In a second step, we argue that the non-pricing distortion $D W L_{\beta}^{N P R}$ is small because of a fairly efficient winnowing out of firms.

We emphasize that the arguments below do not imply that the deadweight loss in an aggressive equilibrium is close to zero. Rather, each one speaks to an economic force in the model that serves as a "headwind" that prevents the deadweight loss from becoming excessively large.

Why is the pricing distortion small? There again appears to be no reason for the pricing distortion in an aggressive equilibrium to be small. At the baseline parameterization, the industry evolves into a mature monopoly. Proposition 2 bounds the contribution $C S^{F B}(\mathbf{e})+\Pi^{F B}(\mathbf{e})-(C S(\mathbf{e})+\Pi(\mathbf{e}))$ to the pricing distortion $D W L_{\beta}^{P R}$ by the degree of product differentiation $\sigma$ and the advantage-building motive $U_{1}\left(\mathbf{e}^{1+}\right)-U_{1}(\mathbf{e})$ : 
Proposition 3 Consider a state $\mathbf{e}=(e, 0)$, where $e>0$. Then

$$
\begin{aligned}
& C S^{F B}(\mathbf{e})+\Pi^{F B}(\mathbf{e})-(C S(\mathbf{e})+\Pi(\mathbf{e})) \\
& <\left\{\begin{array}{ccc}
\sigma & \text { if } & 0 \leq U_{1}\left(\mathbf{e}^{1+}\right)-U_{1}(\mathbf{e})<\sigma\left(1+\exp \left(\frac{p_{0}-c(e)}{\sigma}\right)\right), \\
\sigma+\left|U_{1}\left(\mathbf{e}^{1+}\right)-U_{1}(\mathbf{e})\right| & \text { otherwise. }
\end{array}\right.
\end{aligned}
$$

Note that the bound on the right-hand side of equation (19) approaches $\sigma$ as the incumbent firm moves down its learning curve and $U_{1}\left(\mathbf{e}^{1+}\right)-U_{1}(\mathbf{e})$ approaches zero. While Proposition 3 relies on logit demand, the intuition that the threat of substitution to the outside good holds market power in check transcends the logit specification.

Proposition 3 has bite because aggressive equilibria tend to arise when the degree of product differentiation $\sigma$ is low (see Appendix C). This is intuitive: pricing aggressively to marginalize one's rival or altogether force it from the industry is especially attractive if products are close substitutes so that firms on an equal footing would fiercely compete.

Why is the non-pricing distortion small? While an aggressive equilibrium usually involves delayed exit (relative to the first-best planner solution), it involves rather brisk eventual exit. Thus, the industry usually quickly evolves towards the first-best market structure in an aggressive equilibrium, which tends to keep $D W L_{\beta}^{M S}$, and thus $D W L_{\beta}^{N P R}$,

small. The small non-pricing distortion reflects the resulting relatively low net social loss from a suboptimal number of firms. Put another way, in an aggressive equilibrium, this net social loss is small because competition for the market resolves itself quickly and winnows out firms in a fairly efficient way.

\section{Summary and conclusion}

We study industries where price serves as an investment. The investment role arises when a firm's price affects not only its current profit but also its future competitive position vis-àvis its rivals. Competition is dynamic as firms jostle for competitive advantage through the prices they set.

Our starting point is the conjecture that dynamic competition is necessarily fully efficient in our learning-by-doing model because firms merely transfer rents to consumers by pricing aggressively rather than engage in socially wasteful activities as in rent-seeking models. We argue that this conjecture overlooks that dynamic competition extends beyond pricing into exit and entry. As we show in the special case of a two-step learning curve, even if pricing is efficient, exit and entry are not, and there are coordination failures (Bolton \& Harris 1999) 
and wars of attrition (Maynard Smith 1974, Tirole 1988, Bulow \& Klemperer 1999). In sum, dynamic competition when price serves as an investment is not a "magic bullet".

Still, our analysis suggests that in settings where price plays an investment role, dynamic competition is fairly efficient. Deadweight loss tends to be low (Results 11 and 2) and the investment role of price socially beneficial (Result 3). This is surprising because equilibrium behavior and industry dynamics often differ markedly from the first-best planner solution. In particular, dynamic competition tends to lead to too low prices (Result 4), too many firms in the short run and in the long run (Results 5 and 6), and too slow learning (Result 7 ).

So why is dynamic competition fairly efficient? The answer boils down to the key fundamental that gives rise to the investment role of price in the first place: learning-by-doing.

The pricing distortion tends to be the largest contributor to deadweight loss (part (i) of Result 8 and Result 10). Our bounds on the pricing distortion tighten as the incumbent firms move down their learning curves (Propositions 2 and 3). If the industry evolves into a mature duopoly in an accommodative equilibrium, this happens because the demand for the inside goods becomes less elastic as the incumbent firms improve their cost positions relative to the outside good and drive the share of the outside good close to zero. If the industry evolves into a mature monopoly in an aggressive equilibrium, the bound further tightens as the degree of product differentiation decreases and the threat of substitution to the outside good holds market power in check. Moreover, this is precisely when aggressive equilibria tend to arise in the first place.

The non-pricing distortion comprises the exit and entry distortion and the market structure distortion. In an aggressive equilibrium, the non-pricing distortion tends to be low despite the wasteful duplication of setup costs due to over-entry because competition for the market resolves itself quickly and winnows out firms in a fairly efficient way. In an accommodative equilibrium, the non-pricing distortion tends to be higher. However, the market structure distortion tends to partly offset the exit and entry distortion (parts (ii) and (iii) of Result 8 and Result 9 ). Too many firms give rise not only to a social loss from incurred setup costs due to over-entry and forgone scrap values due to under-exit, but also to a social benefit from additional product variety. Learning-by-doing accentuates this benefit by making product variety less costly to procure.

Put simply, when price serves as an investment, dynamic competition is fairly efficient because of the efficiency-enhancing properties of the investment.

From a regulatory perspective, our analysis suggests that in settings where price serves as an investment, the upside from interventions and policies aimed at shaping competition for the market is likely to be limited. As we show in Besanko et al. (2014), blunt pricing conduct restrictions can lead to substantial welfare losses. Although more subtle pricing conduct restrictions can lead to welfare gains, typically by eliminating equilibria that entail predation- 
like behavior, achieving these gains in practice requires detailed knowledge of demand and cost primitives. Unless the regulator executes flawlessly based on this knowledge, it may therefore be preferable not to intervene at all and tolerate the "not so bad" welfare losses that typically arise under dynamic competition.

A caveat to our analysis is that interventions and policies remain appropriate that forestall collusion between firms that otherwise engage in competition for the market or exclusionary practices by these firms, such as forcing customers to sign long-term exclusive contracts. Our analysis should thus be interpreted as suggesting that there is little in the fundamentals of dynamic competition when price serves as an investment that suggests that antitrust actions have a sizeable upside.

\section{Appendix A Omitted expressions}

Exit decision of incumbent firm. The probability of incumbent firm 1 exiting the industry in state $\mathbf{e}^{\prime}$ is

$$
\begin{aligned}
& \phi_{1}\left(\mathbf{e}^{\prime}\right)=1-F_{X}\left(\widehat{X}_{1}\left(\mathbf{e}^{\prime}\right)\right) \\
& =\left\{\begin{array}{ccc}
1 & \text { if } & \widehat{X}_{1}\left(\mathbf{e}^{\prime}\right)<\bar{X}-\Delta_{X}, \\
\frac{1}{2}-\frac{\left[\widehat{X}_{1}\left(\mathbf{e}^{\prime}\right)-\bar{X}\right]}{2 \Delta_{X}} & \text { if } & \widehat{X}_{1}\left(\mathbf{e}^{\prime}\right) \in\left[\bar{X}-\Delta_{X}, \bar{X}+\Delta_{X}\right], \\
0 & \text { if } & \widehat{X}_{1}\left(\mathbf{e}^{\prime}\right)>\bar{X}+\Delta_{X}
\end{array}\right.
\end{aligned}
$$

and the expectation of the scrap value conditional on exiting the industry is

$$
\begin{aligned}
E_{X}\left[X_{1} \mid X_{1} \geq \widehat{X}_{1}\left(\mathbf{e}^{\prime}\right)\right] & =\frac{\int_{F_{X}^{-1}\left(1-\phi_{1}\left(\mathbf{e}^{\prime}\right)\right)}^{\bar{X}} X_{1} d F_{X}\left(X_{1}\right)}{\phi_{1}\left(\mathbf{e}^{\prime}\right)} \\
& =\frac{1}{\phi_{1}\left(\mathbf{e}^{\prime}\right)}\left[Z_{X}(0)-Z_{X}\left(1-\phi_{1}\left(\mathbf{e}^{\prime}\right)\right)\right]
\end{aligned}
$$

where

$$
Z_{X}(1-\phi)=\frac{1}{\Delta_{X}^{2}}\left\{\begin{array}{ccc}
-\frac{1}{6}\left(\bar{X}-\Delta_{X}\right)^{3} & \text { if } & 1-\phi \leq 0, \\
\frac{1}{2}\left(\Delta_{X}-\bar{X}\right)\left(F_{X}^{-1}(1-\phi)\right)^{2}+\frac{1}{3}\left(F_{X}^{-1}(1-\phi)\right)^{3} & \text { if } & 1-\phi \in\left[0, \frac{1}{2}\right], \\
\frac{1}{2}\left(\Delta_{X}+\bar{X}\right)\left(F_{X}^{-1}(1-\phi)\right)^{2}-\frac{1}{3}\left(F_{X}^{-1}(1-\phi)\right)^{3}-\frac{1}{3} \bar{X}^{3} & \text { if } & 1-\phi \in\left[\frac{1}{2}, 1\right] \\
\frac{1}{6}\left(\bar{X}+\Delta_{X}\right)^{3}-\frac{1}{3} \bar{X}^{3} & \text { if } & 1-\phi \geq 1
\end{array}\right.
$$

and

$$
F_{X}^{-1}(1-\phi)=\bar{X}+\Delta_{X}\left\{\begin{array}{ccc}
-1 & \text { if } & 1-\phi \leq 0 \\
-1+\sqrt{2(1-\phi)} & \text { if } & 1-\phi \in\left[0, \frac{1}{2}\right] \\
1-\sqrt{2 \phi} & \text { if } & 1-\phi \in\left[\frac{1}{2}, 1\right] \\
1 & \text { if } & 1-\phi \geq 1
\end{array}\right.
$$


Entry decision of potential entrant. The probability of potential entrant 1 not entering the industry in state $\mathbf{e}^{\prime}$ is

$$
\begin{aligned}
\phi_{1}\left(\mathbf{e}^{\prime}\right)= & 1-F_{S}\left(\widehat{S}_{1}\left(\mathbf{e}^{\prime}\right)\right) \\
& =\left\{\begin{array}{clc}
1 & \text { if } & \widehat{S}_{1}\left(\mathbf{e}^{\prime}\right)<\bar{S}-\Delta_{S}, \\
\frac{1}{2}-\frac{\left[\widehat{S}_{1}\left(\mathbf{e}^{\prime}\right)-\bar{S}\right]}{2 \Delta_{S}} & \text { if } & \widehat{S}_{1}\left(\mathbf{e}^{\prime}\right) \in\left[\bar{S}-\Delta_{S}, \bar{S}+\Delta_{S}\right], \\
0 & \text { if } & \widehat{S}_{1}\left(\mathbf{e}^{\prime}\right)>\bar{S}+\Delta_{S}
\end{array}\right.
\end{aligned}
$$

and the expectation of the setup cost conditional on entering the industry is

$$
\begin{aligned}
E_{S}\left[S_{1} \mid S_{1} \leq \widehat{S}_{1}\left(\mathbf{e}^{\prime}\right)\right] & =\frac{\int_{\bar{S}-\Delta_{S}}^{F_{S}^{-1}\left(1-\phi_{1}\left(\mathbf{e}^{\prime}\right)\right)} S_{1} d F_{S}\left(S_{1}\right)}{\left(1-\phi_{1}\left(\mathbf{e}^{\prime}\right)\right)} \\
& =\frac{1}{\phi_{1}\left(\mathbf{e}^{\prime}\right)}\left[Z_{S}\left(1-\phi_{1}\left(\mathbf{e}^{\prime}\right)\right)-Z_{S}(1)\right]
\end{aligned}
$$

where

$Z_{S}(1-\phi)=\frac{1}{\Delta_{S}^{2}}\left\{\begin{array}{clc}-\frac{1}{6}\left(\bar{S}-\Delta_{S}\right)^{3} & \text { if } & 1-\phi \leq 0, \\ \frac{1}{2}\left(\Delta_{S}-\bar{S}\right)\left(F_{S}^{-1}(1-\phi)\right)^{2}+\frac{1}{3}\left(F_{S}^{-1}(1-\phi)\right)^{3} & \text { if } & 1-\phi \in\left[0, \frac{1}{2}\right], \\ \frac{1}{2}\left(\Delta_{S}+\bar{S}\right)\left(F_{S}^{-1}(1-\phi)\right)^{2}-\frac{1}{3}\left(F_{S}^{-1}(1-\phi)\right)^{3}-\frac{1}{3} \bar{S}^{3} & \text { if } & 1-\phi \in\left[\frac{1}{2}, 1\right], \\ \frac{1}{6}\left(\bar{S}+\Delta_{S}\right)^{3}-\frac{1}{3} \bar{S}^{3} & \text { if } & 1-\phi \geq 1\end{array}\right.$

and

$$
F_{S}^{-1}(1-\phi)=\bar{S}+\Delta_{S}\left\{\begin{array}{ccc}
-1 & \text { if } & 1-\phi \leq 0 \\
-1+\sqrt{2(1-\phi)} & \text { if } & 1-\phi \in\left[0, \frac{1}{2}\right] \\
1-\sqrt{2 \phi} & \text { if } & 1-\phi \in\left[\frac{1}{2}, 1\right] \\
1 & \text { if } & 1-\phi \geq 1
\end{array}\right.
$$

Producer surplus (decentralized exit and entry). Producer surplus in state e is

$$
P S(\mathbf{e})=\sum_{n=1}^{2} P S_{n}(\mathbf{e}),
$$

where

$$
\begin{gathered}
P S_{1}(\mathbf{e})=\Pi_{1}(\mathbf{e})+\sum_{n=0}^{2} D_{n}(\mathbf{p}(\mathbf{e}))\left\{1\left[e_{1}>0\right] \phi_{1}\left(\mathbf{e}^{n+}\right) E_{X}\left[X_{1} \mid X_{1} \geq \widehat{X}_{1}\left(\mathbf{e}^{n+}\right)\right]\right. \\
\left.-1\left[e_{1}=0\right]\left(1-\phi_{1}\left(\mathbf{e}^{n+}\right)\right) E_{S}\left[S_{1} \mid S_{1} \leq \widehat{S}_{1}\left(\mathbf{e}^{n+}\right)\right]\right\}
\end{gathered}
$$

is producer surplus of firm 1 in state e with

$$
\Pi_{1}(\mathbf{e})=D_{1}(\mathbf{p}(\mathbf{e}))\left(p_{1}(\mathbf{e})-c\left(e_{1}\right)\right) .
$$

$P S_{2}(\mathbf{e})$ and $\Pi_{2}(\mathbf{e})$ are analogous. 
Producer surplus (centralized exit and entry). Producer surplus in state e is

$$
\begin{gathered}
\operatorname{PS}^{F B}(\mathbf{e})=\Pi^{F B}(\mathbf{e})+\sum_{n=0}^{2} D_{n}\left(\mathbf{p}^{F B}(\mathbf{e})\right) \\
\times\left\{\psi_{1,1}^{F B}\left(\mathbf{e}^{n+}\right) E_{\mathbf{X}, \mathbf{S}}\left[-1\left[e_{1}=0\right] S_{1}-1\left[e_{2}=0\right] S_{2} \mid U^{F B}\left(\mathbf{e}^{n+}, \mathbf{X}, \mathbf{S}\right)=U_{1,1}^{F B}\left(\mathbf{e}^{n+}, \mathbf{X}, \mathbf{S}\right)\right]\right. \\
+\psi_{1,0}^{F B}\left(\mathbf{e}^{n+}\right) E_{\mathbf{X}, \mathbf{S}}\left[-1\left[e_{1}=0\right] S_{1}+1\left[e_{2}>0\right] X_{2} \mid U^{F B}\left(\mathbf{e}^{n+}, \mathbf{X}, \mathbf{S}\right)=U_{1,0}^{F B}\left(\mathbf{e}^{n+}, \mathbf{X}, \mathbf{S}\right)\right] \\
+\psi_{0,1}^{F B}\left(\mathbf{e}^{n+}\right) E_{\mathbf{X}, \mathbf{S}}\left[1\left[e_{1}>0\right] X_{1}-1\left[e_{2}=0\right] S_{2} \mid U^{F B}\left(\mathbf{e}^{n+}, \mathbf{X}, \mathbf{S}\right)=U_{0,1}^{F B}\left(\mathbf{e}^{n+}, \mathbf{X}, \mathbf{S}\right)\right] \\
\left.+\psi_{0,0}^{F B}\left(\mathbf{e}^{n+}\right) E_{\mathbf{X}, \mathbf{S}}\left[1\left[e_{1}>0\right] X_{1}+1\left[e_{2}>0\right] X_{2} \mid U^{F B}\left(\mathbf{e}^{n+}, \mathbf{X}, \mathbf{S}\right)=U_{0,0}^{F B}\left(\mathbf{e}^{n+}, \mathbf{X}, \mathbf{S}\right)\right]\right\}
\end{gathered}
$$

with $\Pi^{F B}(\mathbf{e})=\sum_{n=1}^{2} D_{n}\left(\mathbf{p}^{F B}(\mathbf{e})\right)\left(p_{n}^{F B}(\mathbf{e})-c\left(e_{n}\right)\right)$ and $\mathbf{p}^{F B}(\mathbf{e})=\left(p_{1}^{F B}(\mathbf{e}), p_{2}^{F B}(\mathbf{e})\right)$.

Industry structure, conduct, and performance. The expected short-run and long-run number of firms is

$$
N_{1}=\sum_{\mathbf{e}} \mu_{1}(\mathbf{e}) N(\mathbf{e}), \quad N_{\infty}=\sum_{\mathbf{e}} \mu_{\infty}(\mathbf{e}) N(\mathbf{e})
$$

where number of firms in state $\mathbf{e}$ is

$$
N(\mathbf{e})=\sum_{n=1}^{2} 1\left[e_{n}>0\right] .
$$

The expected long-run average price is

$$
\bar{p}_{\infty}=\sum_{\mathbf{e} \geq(0,0)} \frac{\mu_{\infty}(\mathbf{e})}{1-\mu_{\infty}(0,0)} \bar{p}(\mathbf{e}),
$$

where (share-weighted) average price in state $\mathbf{e}$ is

$$
\bar{p}(\mathbf{e})=\sum_{n=1}^{2} \frac{D_{n}\left(p_{1}(\mathbf{e}), p_{2}(\mathbf{e})\right)}{1-D_{0}\left(p_{1}(\mathbf{e}), p_{2}(\mathbf{e})\right)} p_{n}(\mathbf{e}) .
$$

The expected time to maturity is

$$
T^{m}=E\left[\min \left\{t \geq 0 \mid \mathbf{e}_{t} \in \Omega\right\} \mid \mathbf{e}_{0}=(0,0)\right],
$$

where $\mathbf{e}_{t}$ is the state of the industry in period $t$ and

$$
\Omega=\{(m, 0), \ldots,(M, 0),(0, m), \ldots,(0, M),(m, m), \ldots,(M, M)\}
$$

is the set of states in which the industry is either a mature monopoly or a mature duopoly. $\min \left\{t \geq 0 \mid \mathbf{e}_{t} \in \Omega\right\}$ is the so-called first passage time into the set of states $\Omega$. It can be shown that $T^{m}$ is the solution to a system of linear equations (Kulkarni 1995, equation (4.72)).

The expected NPV of consumer surplus $C S_{\beta}$ is defined analogously to the expected NPV 
of total surplus $T S_{\beta}$ in equation (11).

\section{Appendix B Proofs}

Proof of Proposition 1. The proof proceeds in two steps. First, we show that given the policy functions, the value functions solve the Bellman equations (2), (3), and (4). Second, we show that there is no profitable one-shot deviation in any state of the industry. The details of this analysis are presented in the Online Appendix.

Proof of Proposition 2, Define the sum of consumer surplus and static profit to be

$$
\Phi(p)=C S(p, p)+2 D_{1}(p, p)(p-c(e)) .
$$

Using this definition, in a symmetric state $\mathbf{e}=(e, e)$, where $e>0$, we can write

$$
C S^{F B}(\mathbf{e})+\Pi^{F B}(\mathbf{e})-(C S(\mathbf{e})+\Pi(\mathbf{e}))=\Phi\left(p_{1}^{F B}(\mathbf{e})\right)-\Phi\left(p_{1}(\mathbf{e})\right) .
$$

We have

$$
\begin{gathered}
\Phi^{\prime}(p)=-\frac{1}{\sigma}(p-c(e)) D_{0}(p, p)\left(1-D_{0}(p, p)\right), \\
\Phi^{\prime \prime}(p)=-\frac{1}{\sigma^{2}}\left((p-c(e))\left(1-2 D_{0}(p, p)\right)+\sigma\right) D_{0}(p, p)\left(1-D_{0}(p, p)\right) .
\end{gathered}
$$

Hence, $\Phi(p)$ is strictly quasiconcave in $p$ and attains its maximum at $p=c(e)$. Thus, we obtain

$$
C S^{F B}(\mathbf{e})+\Pi^{F B}(\mathbf{e})-(C S(\mathbf{e})+\Pi(\mathbf{e})) \leq \Phi(c(e))-\Phi\left(p_{1}(\mathbf{e})\right) .
$$

We bound the right-hand side of equation (22). Let $\widetilde{p}$ be such that $D_{0}(\widetilde{p}, \widetilde{p})=\frac{1}{2}$, so $1-2 D_{0}(p, p) \geq 0$ for all $p \leq \widetilde{p}$ because $D_{0}(p, p)$ increases in $p$. Equation (21) implies that $\Phi(p)$ is strictly concave in $p$ over the interval $[c(e), \widetilde{p}]$. This interval is non-empty: the assumption $p_{0} \geq \kappa$ coupled with $\kappa \geq c(e)$ implies $D_{0}(c(e), c(e)) \leq D_{0}(\kappa, \kappa) \leq \frac{1}{3}<\frac{1}{2}=D_{0}(\widetilde{p}, \widetilde{p})$. As $D_{0}(p, p)$ increases in $p$, it must be that $c(e)<\widetilde{p}$.

By assumption, $p_{1}(\mathbf{e}) \in[c(e), \widetilde{p}]$. From Theorem 21.2 in Simon \& Blume (1994) and equation (20) we therefore have

$$
\begin{gathered}
\Phi(c(e))-\Phi\left(p_{1}(\mathbf{e})\right) \leq \Phi^{\prime}\left(p_{1}(\mathbf{e})\right)\left(c(e)-p_{1}(\mathbf{e})\right) \\
=\frac{\left(p_{1}(\mathbf{e})-c(e)\right)^{2}}{\sigma} D_{0}\left(p_{1}(\mathbf{e}), p_{1}(\mathbf{e})\right)\left(1-D_{0}\left(p_{1}(\mathbf{e}), p_{1}(\mathbf{e})\right)\right) .
\end{gathered}
$$

This establishes Proposition 2 .

Proof of Proposition 3. Define the sum of consumer surplus and static profit to be

$$
\Phi(p)=C S(p, \infty)+D_{1}(p, \infty)(p-c(e)) .
$$

Using this definition, in a state $\mathbf{e}=(e, 0)$, where $e>0$, we can write

$$
C S^{F B}(\mathbf{e})+\Pi^{F B}(\mathbf{e})-(C S(\mathbf{e})+\Pi(\mathbf{e}))=\Phi\left(p_{1}^{F B}(\mathbf{e})\right)-\Phi\left(p_{1}(\mathbf{e})\right) .
$$


We have

$$
\begin{gathered}
\Phi^{\prime}(p)=-\frac{1}{\sigma}(p-c(e)) D_{0}(p, \infty)\left(1-D_{0}(p, \infty)\right), \\
\Phi^{\prime \prime}(p)=-\frac{1}{\sigma^{2}}\left((p-c(e))\left(1-2 D_{0}(p, \infty)\right)+\sigma\right) D_{0}(p, \infty)\left(1-D_{0}(p, \infty)\right) .
\end{gathered}
$$

Hence, $\Phi(p)$ is strictly quasiconcave in $p$ and attains its maximum at $p=c(e)$. Thus, we obtain

$$
C S^{F B}(\mathbf{e})+\Pi^{F B}(\mathbf{e})-(C S(\mathbf{e})+\Pi(\mathbf{e})) \leq \Phi(c(e))-\Phi\left(p_{1}(\mathbf{e})\right),
$$

where $\Phi(c(e))=v-c(e)+\sigma \ln \left(1+\exp \left(\frac{c(e)-p_{0}}{\sigma}\right)\right)$.

$p_{1}(\mathbf{e})$ is uniquely determined by the solution to the first-order condition (5); it can be written as

$p_{1}(\mathbf{e})=c(e)-\left[U_{1}\left(\mathbf{e}^{1+}\right)-U_{1}(\mathbf{e})\right]+\sigma\left(1+W\left(\exp \left(\frac{p_{0}-c(e)+\left[U_{1}\left(\mathbf{e}^{1+}\right)-U_{1}(\mathbf{e})\right]}{\sigma}-1\right)\right)\right)$,

where $W(\cdot)$ is the Lambert $W$ function. Defining $x=\frac{p_{0}-c(e)}{\sigma}$ and $y=\frac{U_{1}\left(\mathbf{e}^{1+}\right)-U_{1}(\mathbf{e})}{\sigma}$, this can be further written as

$$
p_{1}(\mathbf{e})=c(e)+\sigma(-y+1+W(\exp (x+y-1))) .
$$

Hence,

$$
\Phi\left(p_{1}(\mathbf{e})\right)=v-c(e)+\sigma\left(\ln \left(\frac{1+W(\exp (x+y-1))}{W(\exp (x+y-1))}\right)+\frac{y}{1+W(\exp (x+y-1))}-1\right)
$$

and

$$
\Phi(c(e))=v-c(e)+\sigma \ln (1+\exp (-x)) .
$$

It follows that

$$
\begin{aligned}
& \Phi(c(e))-\Phi\left(p_{1}(\mathbf{e})\right) \\
= & \sigma\left(\ln (1+\exp (-x))-\ln \left(\frac{1+W(\exp (x+y-1))}{W(\exp (x+y-1))}\right)-\frac{y}{1+W(\exp (x+y-1))}+1\right) \\
= & \sigma\left(\ln (1+\exp (x))-\ln (1+W(\exp (x+y-1)))-W(\exp (x+y-1))+\frac{y W(\exp (x+y-1))}{1+W(\exp (x+y-1))}\right) .
\end{aligned}
$$

Some properties of the Lambert $W$ function are that $W(z)$ is increasing in $z, W(0)=0$, and $W(z \exp (z))=z$ for all $z \geq 0$. 
Case 1: $y<1+\exp (x)$. We first show that if $y<1+\exp (x)$, then

$$
\ln (1+\exp (-x))-\ln \left(\frac{1+W(\exp (x+y-1))}{W(\exp (x+y-1))}\right)+1<1
$$

To see this, note that equation (26) is equivalent to

$$
\begin{gathered}
\ln (1+\exp (-x)) \leq \ln \left(\frac{1+W(\exp (x+y-1))}{W(\exp (x+y-1))}\right) \\
\Leftrightarrow \exp (-x)<\frac{1}{W(\exp (x+y-1))} \\
\Leftrightarrow \exp (x)>W(\exp (x+y-1)) .
\end{gathered}
$$

If $y=1+\exp (x)$, then the right-hand side is $W(\exp (x+\exp (x)))=W(\exp (x) \exp (\exp (x)))=$ $\exp (x)$. Moreover, because $W(z)$ is increasing in $z, \exp (x)>W(\exp (x+y-1))$ for all $y<1+\exp (x)$.

Consider equation (24). From equation (26) it follows that

$$
\Phi(c(e))-\Phi\left(p_{1}(\mathbf{e})\right)<\sigma\left(1-y \frac{1}{1+W(\exp (x+y-1))}\right) .
$$

Moreover, $0<\frac{1}{1+W(\exp (x+y-1))}<1$. Therefore, if $y<0$, then

$$
\Phi(c(e))-\Phi\left(p_{1}(\mathbf{e})\right)<\sigma(1+|y|)
$$

and, if $y \geq 0$, then

$$
\Phi(c(e))-\Phi\left(p_{1}(\mathbf{e})\right)<\sigma
$$

Case 2: $y \geq 1+\exp (x)$. We first show that if $y \geq 1+\exp (x)$, then

$$
\ln (1+\exp (x))-\ln (1+W(\exp (x+y-1)))-W(\exp (x+y-1))<1 .
$$

To see this, note that

$$
\begin{gathered}
\ln (1+\exp (x))-\ln (1+W(\exp (x+y-1)))-W(\exp (x+y-1)) \\
\leq \ln (1+\exp (x))-\ln (1+W(\exp (x+\exp (x))))-W(\exp (x+\exp (x))) \\
=\ln (1+\exp (x))-\ln (1+\exp (x))-\exp (x)=-\exp (x)<1 .
\end{gathered}
$$

Consider equation (25). From equation (29) it follows that

$$
\Phi(c(e))-\Phi\left(p_{1}(\mathbf{e})\right)<\sigma\left(1+y \frac{W(\exp (x+y-1))}{1+W(\exp (x+y-1))}\right) .
$$

Moreover, $0<\frac{W(\exp (x+y-1))}{1+W(\exp (x+y-1))}<1$. Because $y \geq 1+\exp (x)>0$, we have

$$
\Phi(c(e))-\Phi\left(p_{1}(\mathbf{e})\right)<\sigma(1+y) .
$$


Collecting equations (27), (28), and (30) establishes Proposition 3 ,

\section{Appendix C Aggressive and accommodative equilibria}

We offer formal definitions of aggressive and accommodative equilibria, but note from the outset that any attempt to classify equilibria is fraud with difficulty because the different equilibria lie on a continuum and thus morph into each other in complicated ways as we vary the parameters of the model.

Our definition of an aggressive equilibrium hones in on a trench in the pricing decision, and our definition of an accommodative equilibrium on a lack of exit from a duopolistic industry:

Definition 1 An equilibrium is aggressive if

$$
p_{1}(\mathbf{e})<p_{1}\left(e_{1}, e_{2}+1\right), \quad p_{2}(\mathbf{e})<p_{2}\left(e_{1}, e_{2}+1\right), \quad \phi_{2}(\mathbf{e})>\phi_{2}\left(e_{1}, e_{2}+1\right)
$$

for some state $\mathbf{e}>(0,0)$ with $e_{1}>e_{2}$.

Definition 2 An equilibrium is accommodative if

$$
\phi_{1}(\mathbf{e})=\phi_{2}(\mathbf{e})=0
$$

for all states $\mathbf{e}>(0,0)$.

These definitions are not exhaustive. The percentage of equilibria classified as aggressive is $96.88 \%$, the percentage of equilibria classified as accommodative is $1.99 \%$, and the percentage of unclassified equilibria is $1.13 \%$. Our computations always led to a unique accommodative equilibrium but often to multiple aggressive equilibria at a given parameterization.

An aggressive equilibrium exists if the degree of product differentiation $\sigma$ is sufficiently low. As competition in a duopolististic industry becomes fiercer, monopolizing the industry becomes more attractive. Other factors contributing to the existence of an aggressive equilibrium are a high expected scrap value $\bar{X}$ and a high price of the outside good $p_{0}$. The first factor makes it easier for a firm to induce its rival to exit the industry and the second makes monopolizing the industry more attractive by allowing the surviving firm to charge a higher price. Conversely, an accommodative equilibrium exists if the degree of product differentiation $\sigma$ is sufficiently high. Other factors contributing to the existence of an accommodative equilibrium are a low expected scrap value $\bar{X}$ and a low price of the outside good $p_{0}$.

Our definitions of aggressive and accommodative equilibria are linked, however imperfectly, to worst, respectively, best equilibria. Table 7 shows that $49.09 \%$ of parameterizations have a unique equilibrium and that the equilibrium is classified as accommodative in $83.40 \%$ of these parameterizations. Moreover, $50.91 \%$ of parameterizations have multiple equilibria and the worst equilibrium is classified as aggressive in $97.96 \%$ of these parameterizations. However, the best equilibrium is classified as accommodative in $40.54 \%$ of these parameterizations and as aggressive in $43.36 \%$ of these parameterizations. This far from perfect link appears to reflect that our definition of an accommodative equilibrium is quite stringent. While there is an aggressive equilibrium at all parameterizations with multiple equilibria, there may 


\begin{tabular}{|c|c|c|c|c|c|}
\hline & \multirow[t]{2}{*}{$\begin{array}{l}\text { unique equilibrium } \\
\qquad 49.09 \% \\
\end{array}$} & \multicolumn{2}{|c|}{$\begin{array}{c}\text { multiple equilibria } \\
50.91 \%\end{array}$} & \multicolumn{2}{|c|}{$\begin{array}{l}\text { multiple equilibria } \\
\text { incl. accomm. eqbm. } \\
21.98 \%\end{array}$} \\
\hline & & best & worst & best & worst \\
\hline aggressive & $3.32 \%$ & $43.36 \%$ & $97.96 \%$ & $5.84 \%$ & $96.85 \%$ \\
\hline accommodative & $83.40 \%$ & $40.54 \%$ & $1.36 \%$ & $93.93 \%$ & $3.15 \%$ \\
\hline unclassified & $13.28 \%$ & $16.10 \%$ & $0.68 \%$ & $0.22 \%$ & $0.00 \%$ \\
\hline
\end{tabular}

Table 7: Percentage of parameterizations with a unique equilibrium, multiple equilibria, and multiple equilibria including an accommodative equilibrium (upper panel) and, within each of these, percentage of parameterizations at which the best or worst equilibrium is aggressive, accommodative, or unclassified (lower panel). Unweighted.

not be an accommodative equilibrium. The rightmost column of Table 7 restricts attention to parameterizations with multiple equilibria that include an accommodative equilibrium. The best equilibrium is classified as accommodative in $93.93 \%$ of these parameterizations and the worst equilibrium is classified as aggressive in $96.85 \%$ of these parameterizations. To facilitate the exposition and build intuition, we therefore associate the best equilibrium with an accommodative equilibrium and the worst equilibrium - to the extent that it differs from the best equilibrium - with an aggressive equilibrium. If the equilibrium is unique, then we associate it with an accommodative equilibrium.

\section{References}

Aghion, P. \& Howitt, P. (1992), 'A model of growth through creative destruction', Econometrica 60(2), 323-351.

Alchian, A. (1963), 'Reliability of progress curves in airframe production', Econometrica 31(4), 679-693.

Anderson, S., de Palma, A. \& Thisse, J. (1992), Discrete choice theory of product differentiation, MIT Press, Cambridge.

Athey, S. \& Schmutzler, A. (2001), 'Investment and market dominance', Rand Journal of Economics 32(1), 1-26.

Baloff, N. (1971), 'Extension of the learning curve: Some empirical results', Operational Research Quarterly 22(4), 329-340.

Benkard, L. (2000), 'Learning and forgetting: The dynamics of aircraft production', American Economic Review 90(4), 1034-1054.

Bergemann, D. \& Välimäki, J. (1996), 'Learning and strategic pricing', Econometrica 64(5), 1125-1149.

Bergemann, D. \& Välimäki, J. (1997), 'Market diffusion with two-sided learning', Rand Journal of Economics 28(4), 773-795. 
Bergemann, D. \& Välimäki, J. (2006), 'Dynamic price competition', Journal of Economic Theory 127, 232-263.

Besanko, D., Doraszelski, U. \& Kryukov, Y. (2014), 'Efficiency or predation: What drives pricing when there is learning-by-doing?', American Economic Review 104(3), 868-897.

Besanko, D., Doraszelski, U., Kryukov, Y. \& Satterthwaite, M. (2010), 'Learning-by-doing, organizational forgetting, and industry dynamics', Econometrica 78(2), 453-508.

Besanko, D., Perry, M. \& Spady, R. (1990), 'The logit model of monopolistic competition: Brand diversity', Journal of Industrial Economics 38(4), 397-415.

Biglaiser, G. \& Cremer, J. (2016), The value of incumbency for heterogeneous platforms, Working paper, Toulouse School of Economics, Toulouse.

Bohn, R. (1995), 'Noise and learning in semiconductor manufacturing', Management Science 41(1), 31-42.

Bolton, P. \& Farrell, J. (1990), 'Decentralization, duplication, and delay', Journal of Political Economy 98(4), 803-826.

Bolton, P. \& Harris, C. (1999), 'Strategic experimentation', Econometrica 67(2), 349-372.

Borkovsky, R., Doraszelski, U. \& Kryukov, Y. (2010), 'A user's guide to solving dynamic stochastic games using the homotopy method', Operations Research 58(4), 1116-1132.

Borkovsky, R., Doraszelski, U. \& Kryukov, Y. (2012), 'A dynamic quality ladder model with entry and exit: Exploring the equilibrium correspondence using the homotopy method', Quantitative Marketing and Economics 10(2), 197-229.

Bulow, J. \& Klemperer, P. (1999), 'The generalized war of attrition', Journal of Political Economy 89(1), 175-189.

Cabral, L. (1993), 'Experience advantages and entry dynamics', Journal of Economic Theory 59, 403-416.

Cabral, L. (2011), 'Dynamic price competition with network effects', Review of Economic Studies 78, 83-111.

Cabral, L. \& Riordan, M. (1994), 'The learning curve, market dominance, and predatory pricing', Econometrica 62(5), 1115-1140.

Caves, R. \& Porter, M. (1977), 'From entry barriers to mobility barriers: Conjectural decisions and contrived deterrence to new competition', Quarterly Journal of Economics 91(2), 241-262.

Chen, J. (2011), How do switching costs affect market concentration and prices in network industries?, Working paper, UC Irvine, Irvine.

Chen, J., Doraszelski, U. \& Harrington, J. (2009), 'Avoiding market dominance: Product compatibility in markets with network effects', Rand Journal of Economics 49(3), 455485. 
Ching, A. (2010), 'A dynamic oligopoly structural model for the prescription drug market after patent expiration', International Economic Review 51(4), 1175-1207.

Dasgupta, P. \& Stiglitz, J. (1988), 'Learning-by-doing, market structure and industrial and trade policies', Oxford Economics Papers 40(2), 246-268.

DeJong, J. (1957), 'The effects of increasing skills on cycle time and its consequences for time standards', Ergonomics 1(1), 51-60.

Dixit, A. \& Stiglitz, J. (1977), 'Monopolistic competition and optimum product diversity', American Economic Review 67(3), 297-308.

Doraszelski, U. \& Escobar, J. (2010), 'A theory of regular Markov perfect equilibria in dynamic stochastic games: Genericity, stability, and purification', Theoretical Economics 5, 369-402.

Doraszelski, U. \& Satterthwaite, M. (2010), 'Computable Markov-perfect industry dynamics', Rand Journal of Economics 41(2), 215-243.

Dube, J., Hitsch, G. \& Chintagunta, P. (2010), 'Tipping and concentration in markets with indirect network effects', Journal of Marketing Research 29(2), 216-249.

Dube, J., Hitsch, G. \& Rossi, P. (2009), 'Do switching costs make markets less competitive?', Journal of Marketing Research 46, 435-445.

Dudley, L. (1972), 'Learning and productivity changes in metal products', American Economic Review 62(4), 662-669.

Ericson, R. \& Pakes, A. (1995), 'Markov-perfect industry dynamics: A framework for empirical work', Review of Economic Studies 62, 53-82.

Evans, D. \& Schmalensee, R. (2002), Some economic aspects of antitrust analysis in dynamically competitive industries, in A. Jaffe, J. Lerner \& S. Stern, eds, 'Innovation policy and the economy', Vol. 2, NBER, Cambridge, pp. 1-49.

Farrell, J. \& Klemperer, P. (2007), Coordination and lock-in: Competition with switching costs and network effects, in M. Armstrong \& R. Porter, eds, 'Handbook of Industrial Organization', Vol. 3, North-Holland, Amsterdam, pp. 1967-2072.

Gruber, H. (1992), 'The learning curve in the production of semiconductor memory chips', Applied Economics 24, 885-894.

Halaburda, H., Jullien, B. \& Yehezkel, Y. (2016), Dynamic competition with network externalities: Why history matters, Working paper, Toulouse School of Economics, Toulouse.

Harberger, A. (1954), 'Monopoly and resource allocation', American Economic Review 44(2), 77-87.

Hatch, N. \& Mowery, D. (1998), 'Process innovation and learning by doing in semiconductor manufacturing', Management Science 44(1), 1461-1477. 
Hirsch, W. (1952), 'Progress functions of machine tool manufacturing', Econometrica 20(1), 81-82.

Hirschmann, W. (1964), 'Profit from the learning curve', Harvard Business Review 42(1), 125-139.

Hopenhayn, H. (1992), 'Entry, exit, and firm dynamics in long-run equilibrium', Econometrica 60(5), 1127-1150.

Irwin, D. \& Klenow, P. (1994), 'Learning-by-doing spillovers in the semiconductor industry', Journal of Political Economy 102(6), 1200-1227.

Jarmin, R. (1994), 'Learning by doing and competition in the early rayon industry', Rand Journal of Economics 25(3), 441-454.

Jorgensen, S. \& Zaccour, G. (2004), Differential games in marketing, Kluwer Academic Publishers, Dordrecht.

Jovanovic, B. (1982), 'Selection and the evolution of industry', Econometrica 50(3), 649-670.

Jun, B. \& Vives, X. (2004), 'Strategic incentives in dynamic duopoly', Journal of Economic Theory 116, 249-281.

Kilbridge, M. (1962), 'A model for industrial learning costs', Management Science 8(4), 516527.

Koenker, R. \& Perry, M. (1981), 'Product differentiation, monopolistic competition, and public policy', Bell Journal of Economics 12, 217-231.

Kulkarni, V. (1995), Modeling and analysis of stochastic systems, Chapman and Hall, London.

Lapham, B. \& Ware, R. (1994), 'Markov puppy dogs and related animals', International Journal of Industrial Organization 12, 569-593.

Levy, F. (1965), 'Adaptation in the production process', Management Science 11(6), 136154.

Lieberman, M. (1984), 'The learning curve and pricing in the chemical processing industries', Rand Journal of Economics 15(2), 213-228.

Maynard Smith, J. (1974), 'Theory of games and the evolution of animal conflicts', Journal of Theoretical Biology 47, 209-221.

Mermelstein, B., Nocke, V., Satterthwaite, M. \& Whinston, M. (2014), Internal versus external growth in industries with scale economies: A computational model of optimal merger policy, Working paper, Northwestern University, Evanston.

Mitchell, M. \& Skrzypacz, A. (2006), 'Network effects and long-run market shares', Economic Theory 29(3), 621-648. 
Pakes, A. \& McGuire, P. (1994), 'Computing Markov-perfect Nash equilibria: Numerical implications of a dynamic differentiated product model', Rand Journal of Economics 25(4), 555-589.

Pisano, G. (1994), 'Knowledge, integration, and the locus of learning: An empirical analysis of process development', Strategic Management Journal 15, 85-100.

Posner, R. (1975), 'The social costs of monopoly and regulation', Journal of Political Economy 83(4), 807-828.

Preston, L. \& Keachie, E. (1964), 'Cost functions and progress functions: An integration', American Economic Review 54(2), 100-107.

Rob, R. (1991), 'Learning and capacity expansion under demand uncertainty', Review of Economic Studies 58(4), 655-675.

Segal, I. \& Whinston, M. (2007), 'Antitrust in innovative industries', American Economic Review 97(5), 1703-1730.

Shafer, S., Nembhard, D. \& Uzumeri, M. (2001), 'The effects of worker learning, forgetting, and heterogeneity on assembly line productivity', Management Science 47(12), 16391653.

Simon, C. \& Blume, L. (1994), Mathematics for economists, Norton, New York.

Thompson, P. (2001), 'How much did the Liberty shipbuilders learn? New evidence for an old case study', Journal of Political Economy 109(1), 103-137.

Thornton, R. \& Thompson, P. (2001), 'Learning from experience and learning from others: An exploration of learning and spillovers in wartime shipbuilding', American Economic Review 91(5), 1350-1368.

Tirole, J. (1988), The theory of industrial organization, MIT Press, Cambridge.

Vettas, N. (1998), 'On entry, exit, and coordination with mixed strategies', European Economic Review 44(2), 1557-1576.

Wright, T. (1936), 'Factors affecting the cost of airplanes', Journal of Aeronautical Sciences 3(4), 122-128.

Zimmerman, M. (1982), 'Learning effects and the commercialization of new energy technologies: The case of nuclear power', Bell Journal of Economics 13(2), 297-310. 